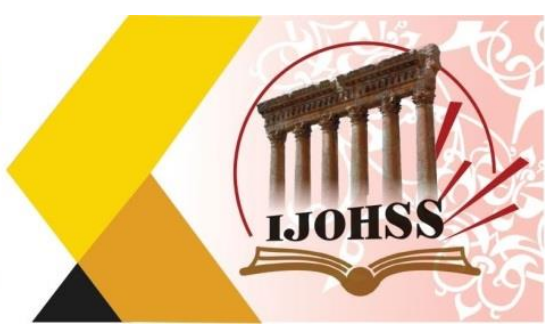

\title{
دور رأس المال الفكري في تحقيق الابداع التقيني \\ (دراسة ميذانيه في شركة اسيا سيل للاتصالات النقال)
}

\author{
نور قصي عبد الرزاق \\ مدرس مساعد - قسم إدارة الأعمال \\ كلية النسور الجامعة. العراق \\ noor.kh.bs@nuc.edu.iq
}

الماخص

تهدف الدراسة الى دراسة دور رأس المال الفكري في تحقيق الابداع التقني من خلال اختبار نماذج العلاقة و الاثر بينهما، إذ ان مشكلة الدراسة تجسدت بتساؤلات منها: هل يساهم رأس المال الفكري في تحقيق الابداع

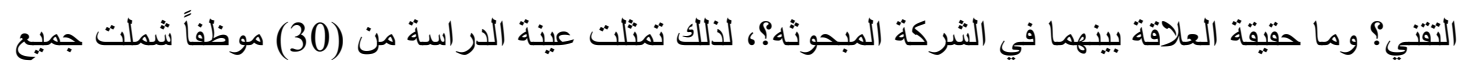
المدراء ومعاونيهم في المستويات الادارية العليا والوسطى والانيا في شركة اسيا سيل للاتصالات النقال. وتم

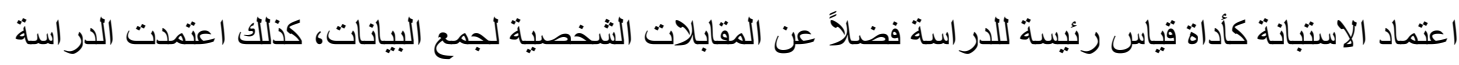
على المنهج الوصفي والتحليلي لعرض البيانات وتحليلها، فقد تم توظيف عدة اساليب احصائية لتحليل هذه البيانات ابرزها (معامل الارتباط (Pearson)، أسلوب تحليل الانحدار البسيط، اختبار F و t). ومن اهم

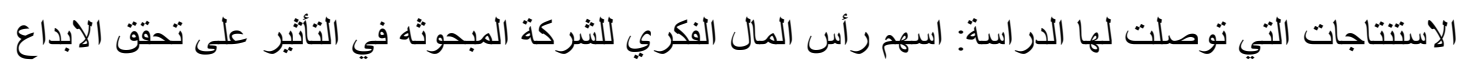
التقني. اما اهم التوصيات التي تقدمها الدراسة: ضرورة اهتمام الثركة بعلاقات بين الرؤساء والمرؤوسين

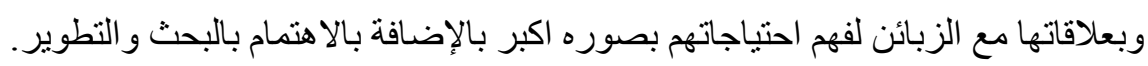

الكلمات المفتاحية: رأس المال الفكري، الابداع التقني. 


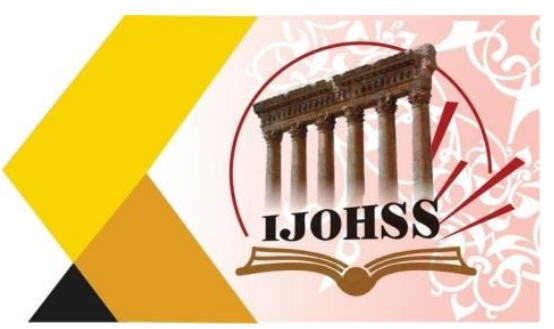

\title{
The role of Intellectual Capital in Achieving Technical Innovation (A field study in Asia Cell for Mobile Communications)
}

\author{
Noor Qusay Abdal-Razzaq \\ Assistant Lecturer - Department of \\ Business Administration \\ Al-Nisour University College -Iraq \\ noor.kh.bs@nuc.edu.iq
}

\begin{abstract}
The study aims to study the role of intellectual capital in achieving technical creativity by examining the relationship and impact models between them, as the study problem was embodied by questions, including: What is the role of intellectual capital in achieving technical creativity? What is the truth about the relationship between them in the researched company? Therefore, the study sample was represented by a sample of (30) employees that included all the managers and their assistants at the upper, middle and lower administrative levels in the Asia Cell Mobile Communications Company. The questionnaire was adopted as a main measurement tool for the study in addition to personal interviews to collect data. The study also relied on the descriptive and analytical approach to present and analyze the data. Several statistical methods were employed to analyze these data, the most prominent of which are (Pearson Correlation Coefficient, Simple Regression Analysis Method, F-Test and t). Among the most important conclusions reached by the study: The intellectual capital of the researched company has influenced the achievement of technical innovation. As for the most important recommendations presented by the study: The need for the company to pay attention to relations between superiors and subordinates and to its relations with customers to understand their needs in a greater way, in addition to paying attention to research and development.
\end{abstract}

Keywords: intellectual capital, technical innovation. 


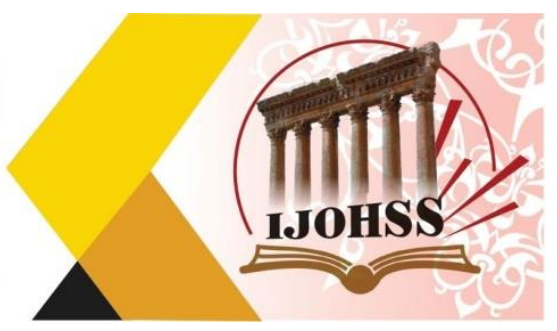

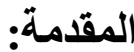

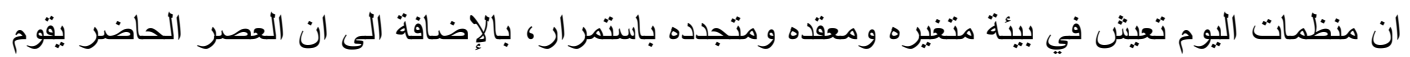

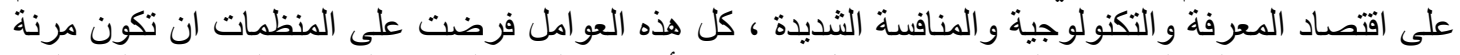

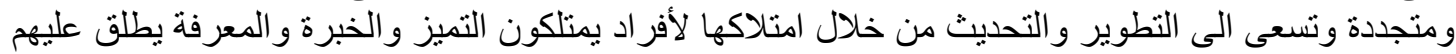

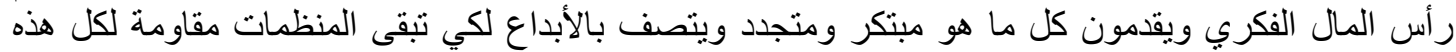

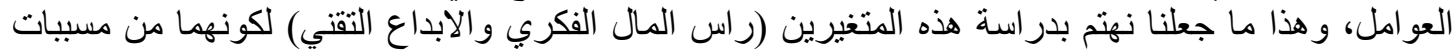

بقاء المنظمات ونجاحها.

اولا: منهجية البحث الجن

1

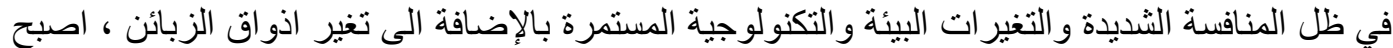

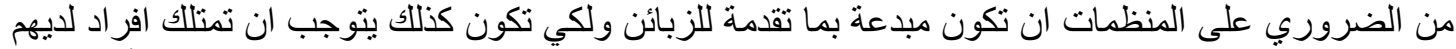

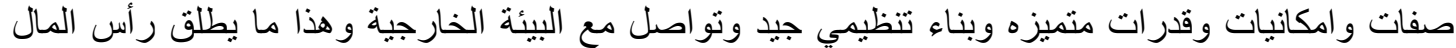

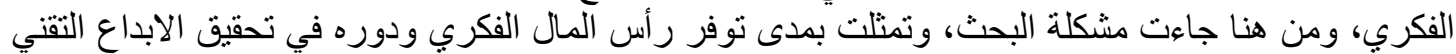

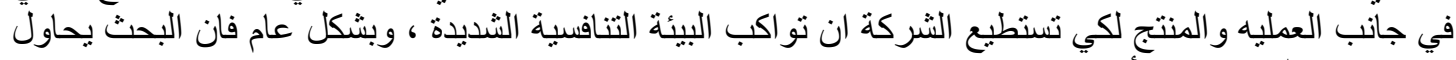
الاجابه عن التساؤلات الآثية:

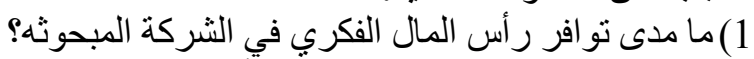

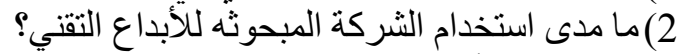
3) هل يساهم رأس المال الفكري في تحقيق الابداع التقني؟

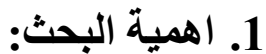

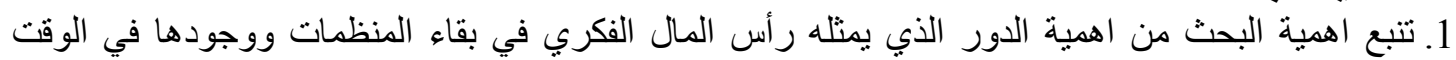

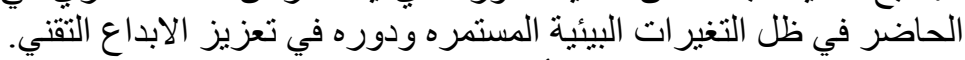

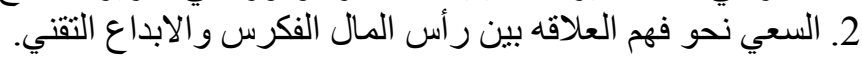

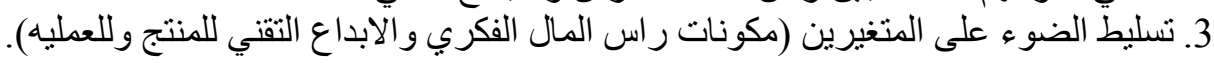

1) ابراز دور رأس المال الفكري والابداع التقني على المستوى التطبيقي والاكاديمي للخروج بمجموعه من

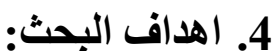

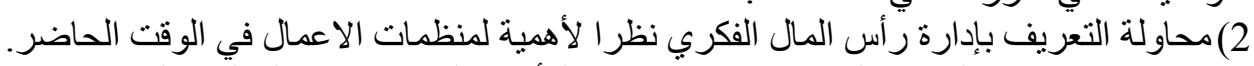

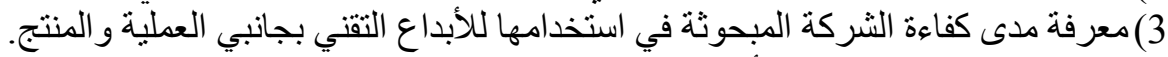

4) معرفة مدى تو افر مكونات رأس المال الفكري في الثركة المبحوثه وكيفية تعزيز ها.

5. ترضيات البحث:

تنبع من مشكلة البحث فرضيت البحث: 1) الفرضيه الاولى: (توجد علاقة فرضئ ارتباط ذات دلالة معنوية بين رأس المال الفكري والابداع التقني ) وتنبع منها

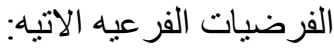

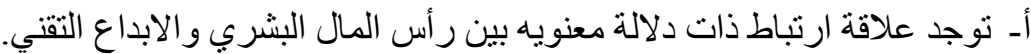

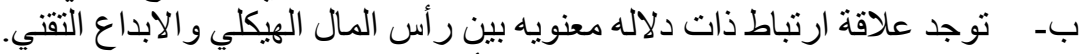

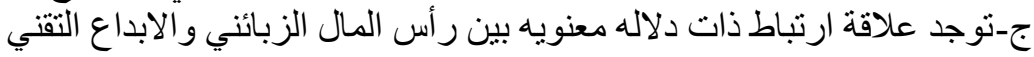


العدد (16) أكتوبر 2020 (16)

Volume (16) October 2020

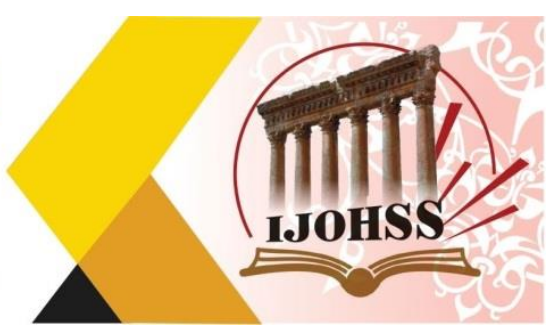

2) الفرضية الثانية: ( يوجد تأثير ذو دلاله معنويه لرأس المال الفكري على الابداع التقني) وتتبع منها الفرضيات الفر عية الأتية:

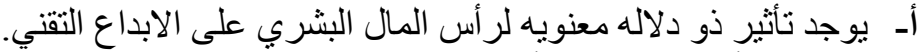

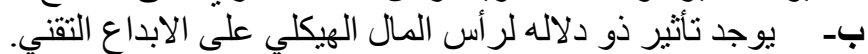

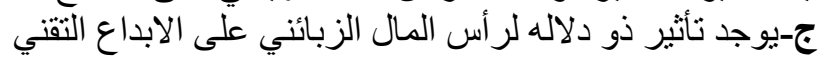

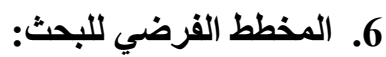

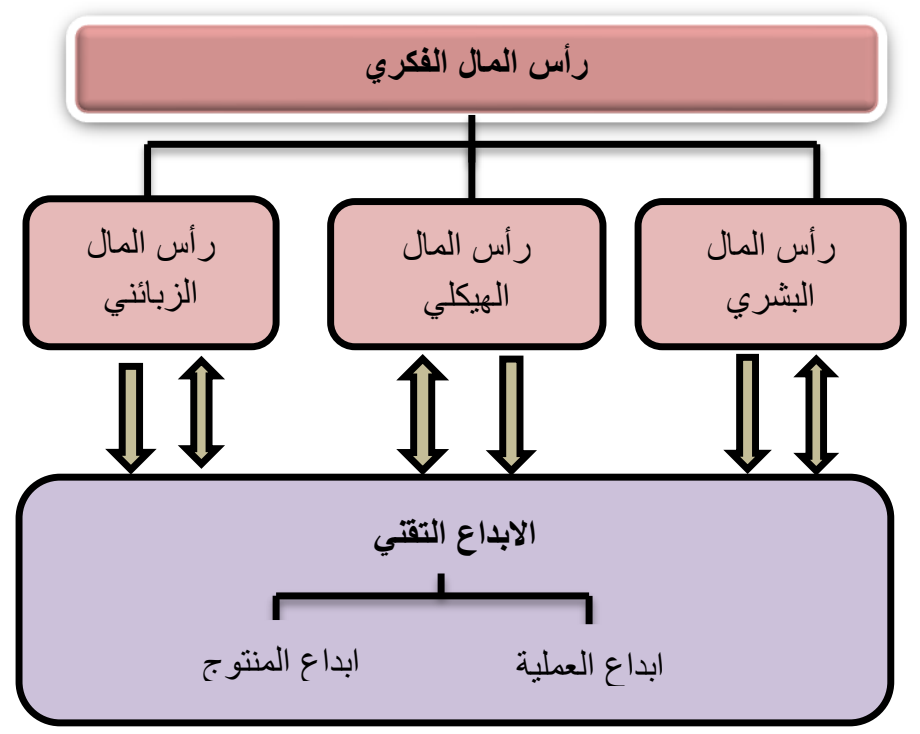

7. - الحدود الدراسة:

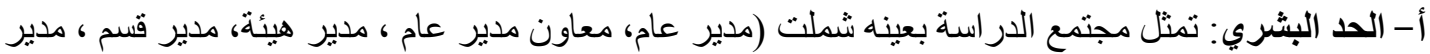

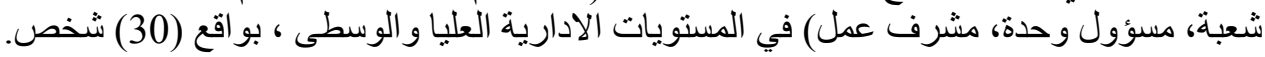

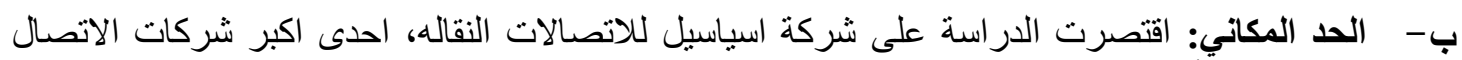
النقال في العر اق وتتأسست عام البعت 1999. ج- الحد الزماني: تم تطبيق هذه الدراسة في العام 2020. ثاتيا: الاطار النظري والاراسات السابقة

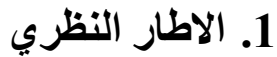

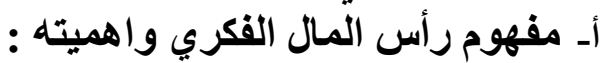

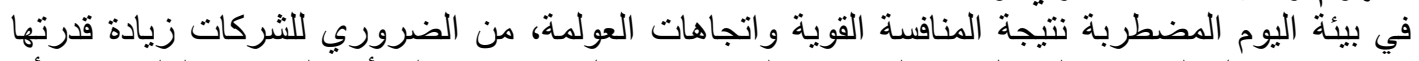

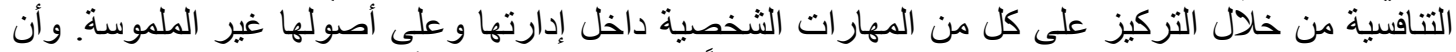

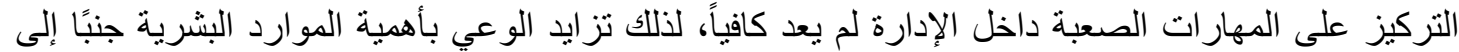

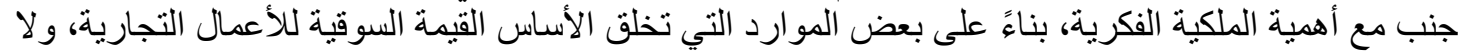

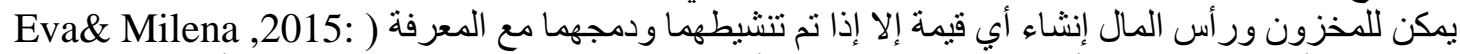
3). وبذلك أصبح مصطلح رأس المال الفكري، الذي أعلنه (John Kenneth Galbraith) لأول مرة في عام النيا 


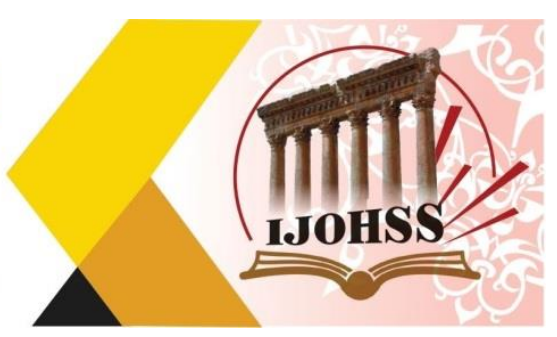

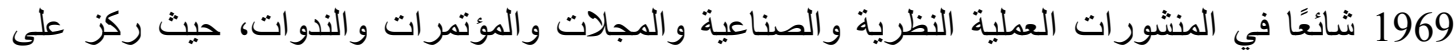

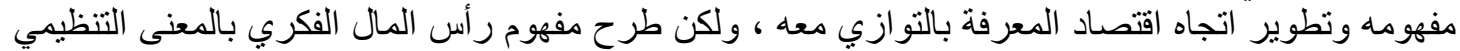

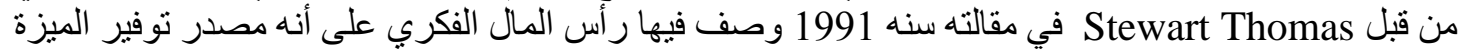

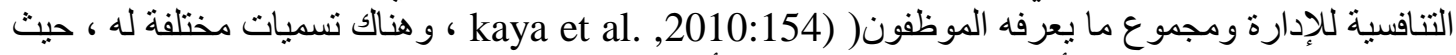

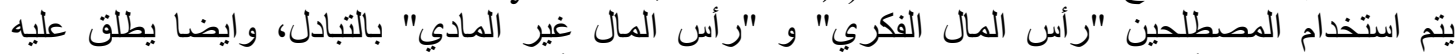

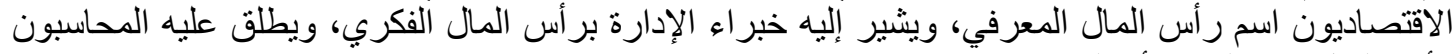

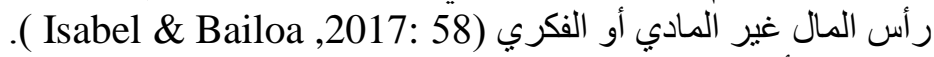

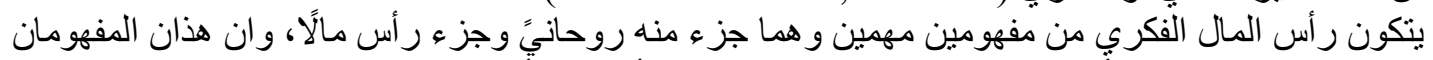

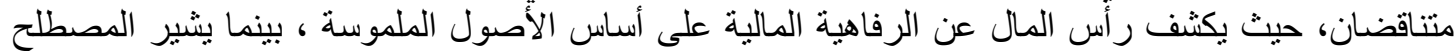

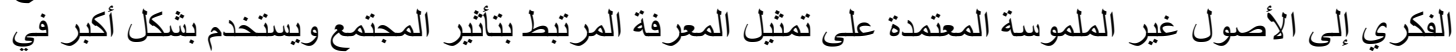

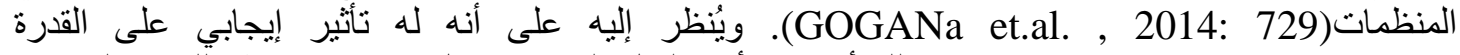

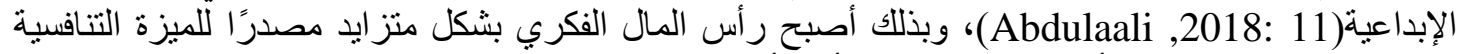

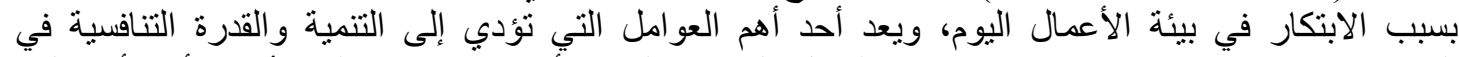

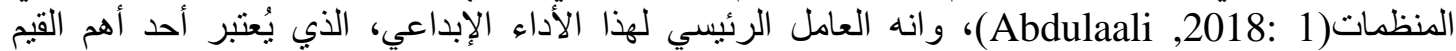

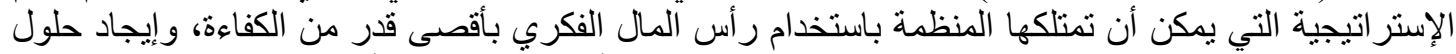

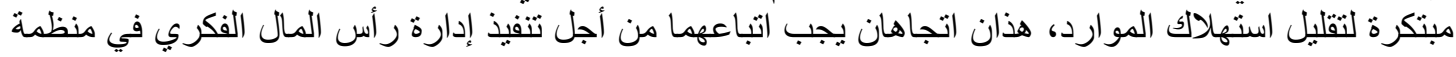

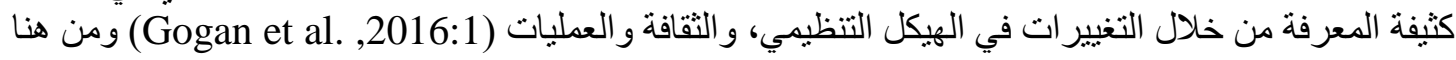

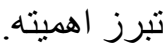

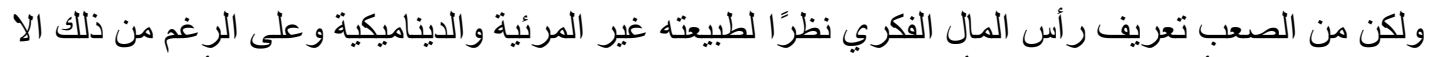

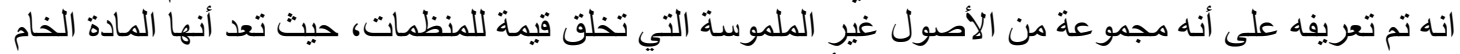

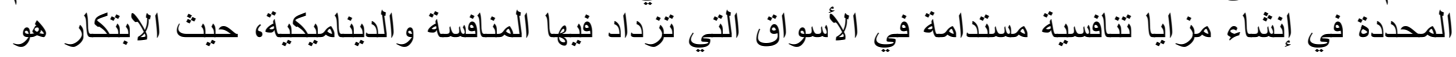

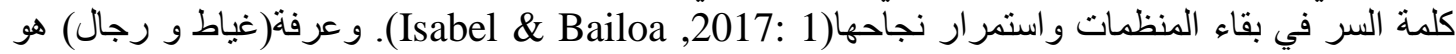

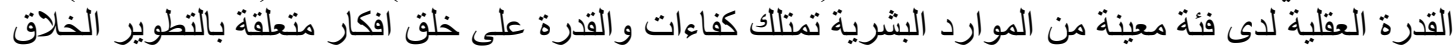

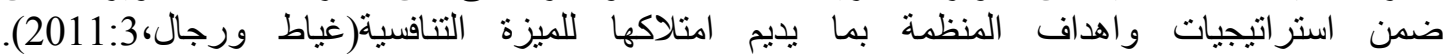

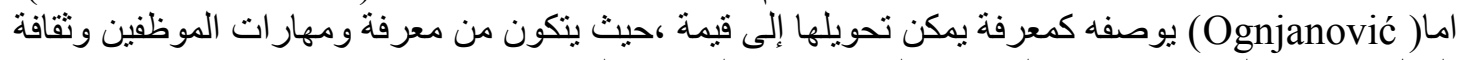

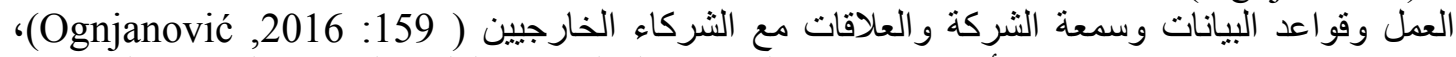

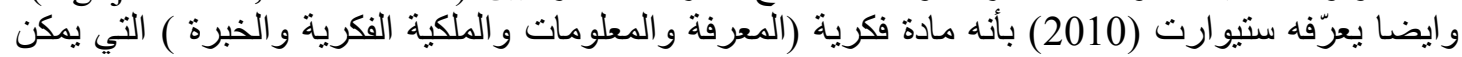

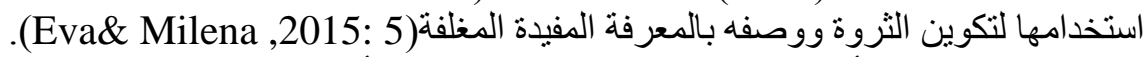

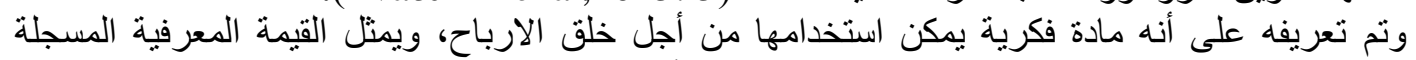

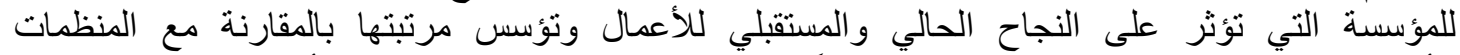

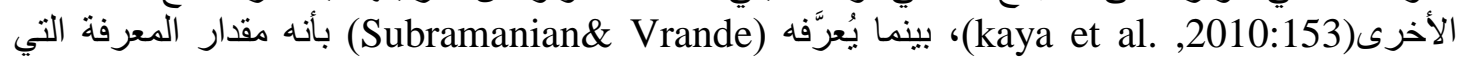

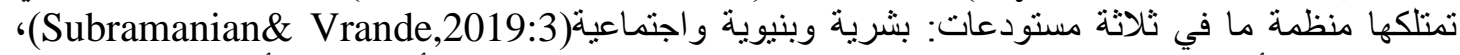

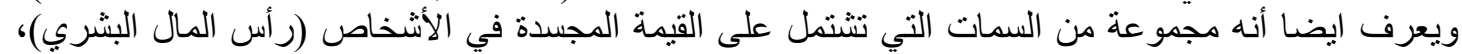

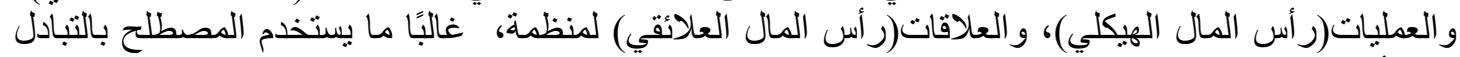

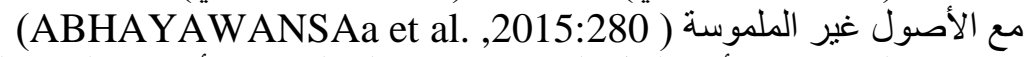

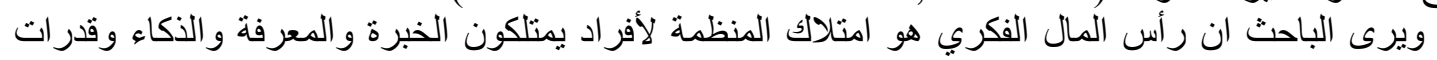

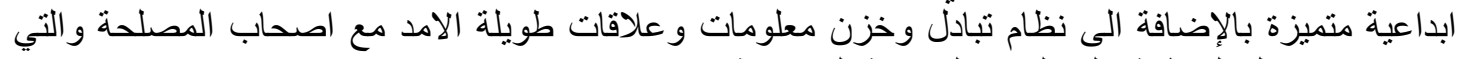

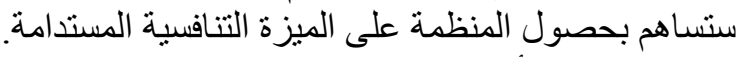

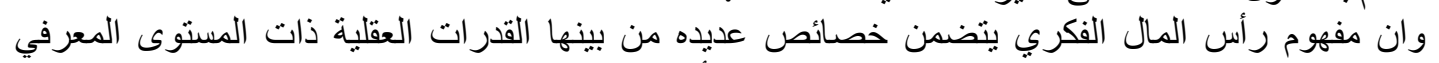

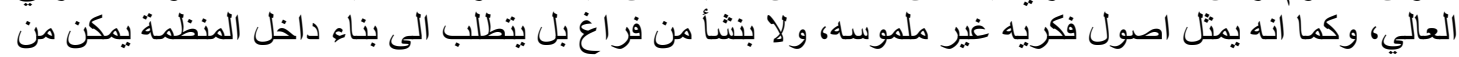

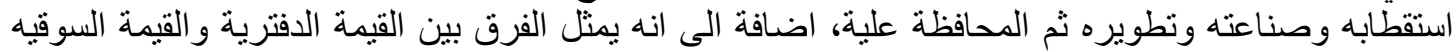

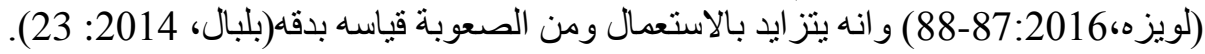

\section{1} DOI: 10.33193/IJoHSS.16.2020.149 


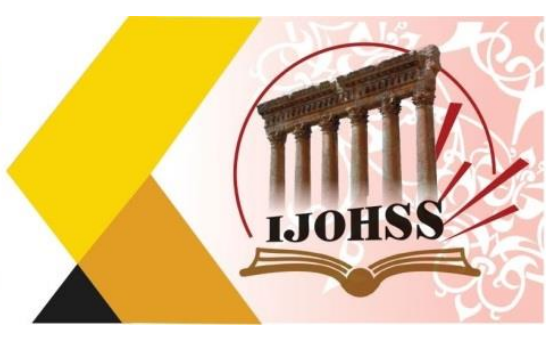

ب- مكونات رأس المال الفكري:

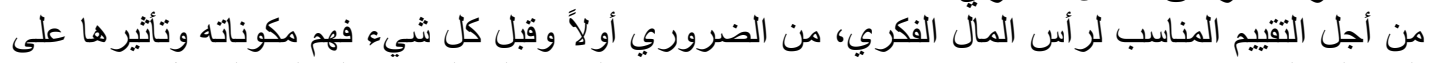

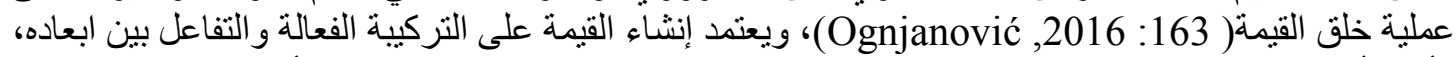

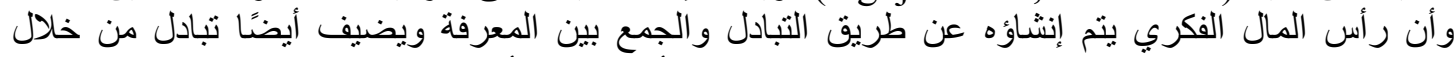

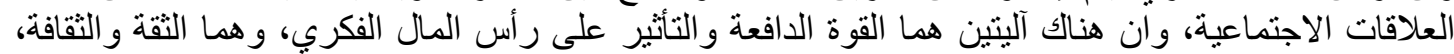

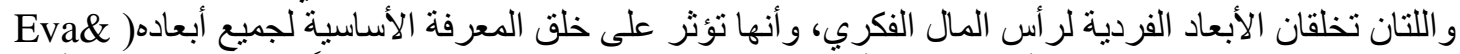

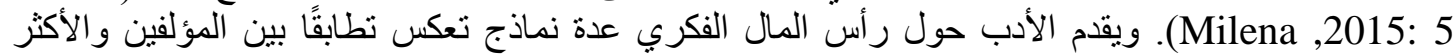

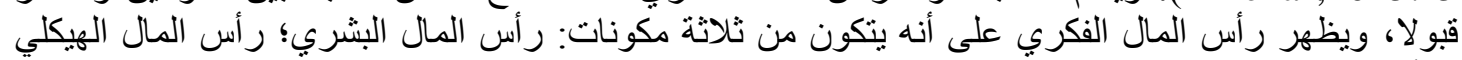

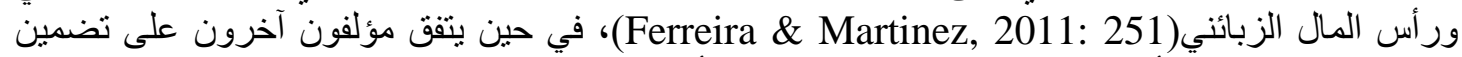

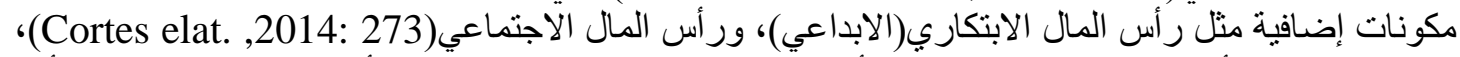

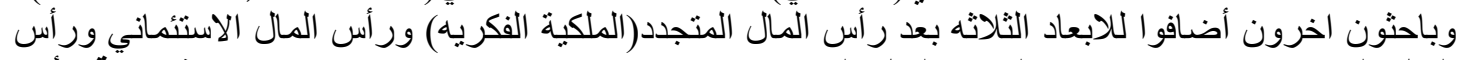

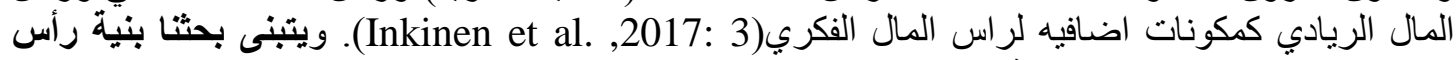

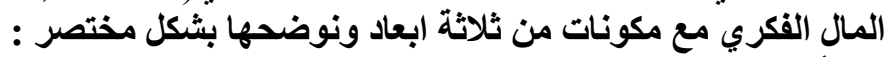

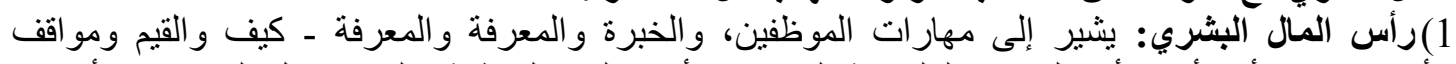

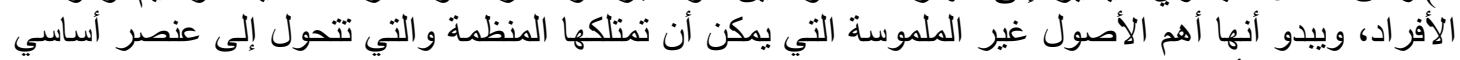

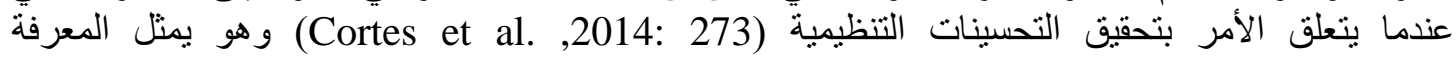

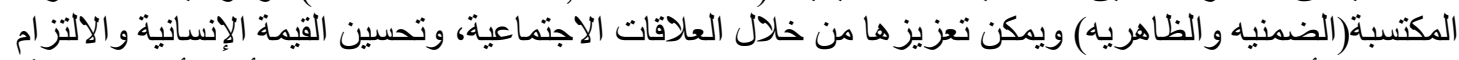

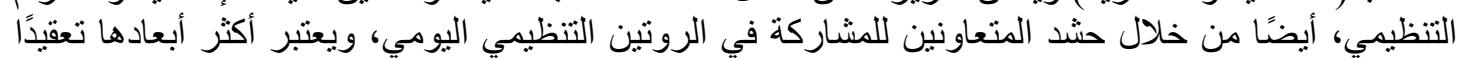

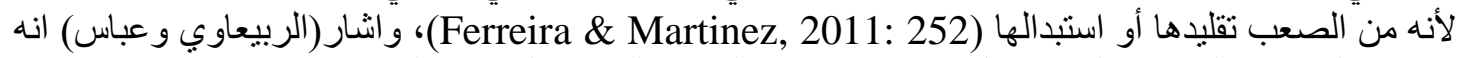

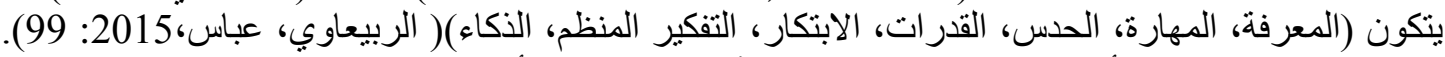

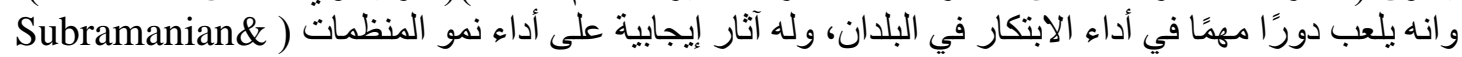
(Vrande,2019:3

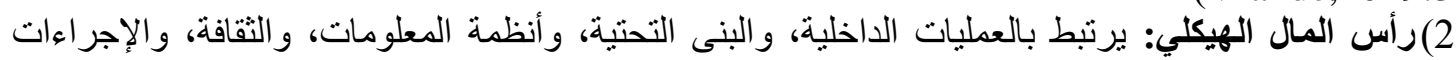

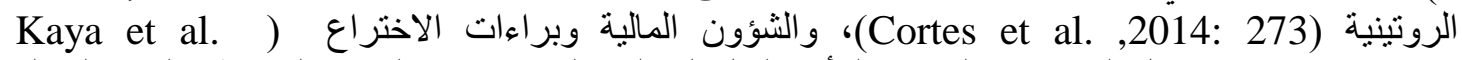

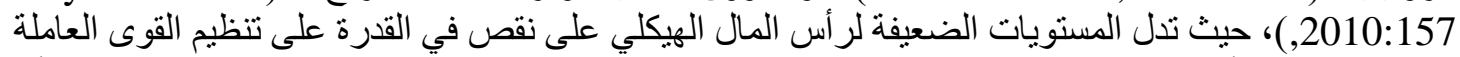

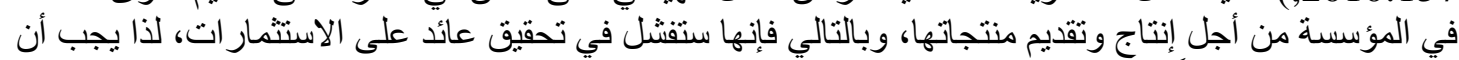

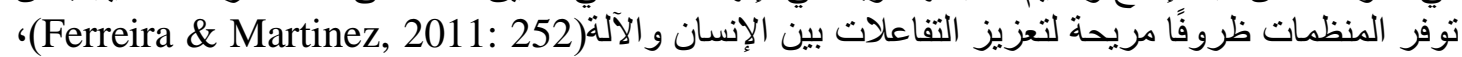

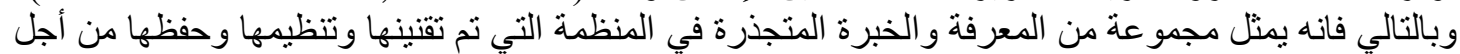
تجميع هذه المعرفة والاحتفاظ بها(Subramanian\& Vrande,2019:3) و انهاله يتكون من العناصرة(النظم،

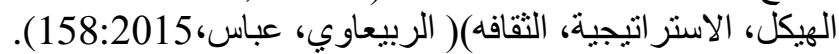

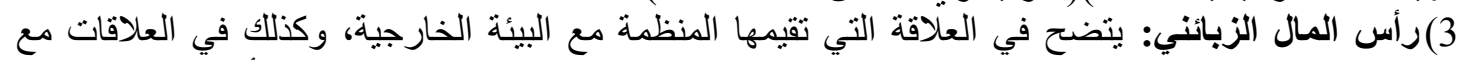

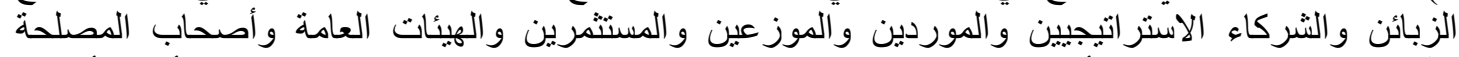

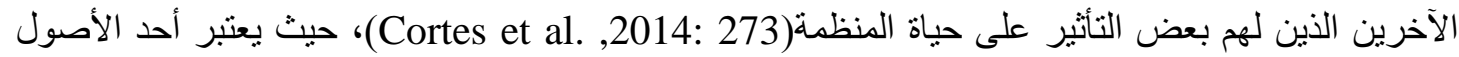

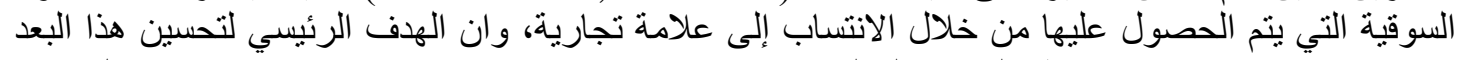

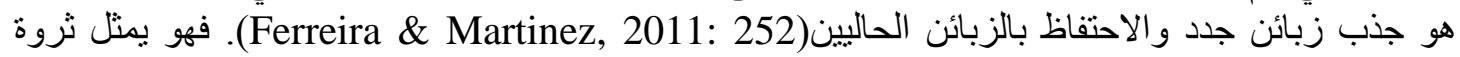

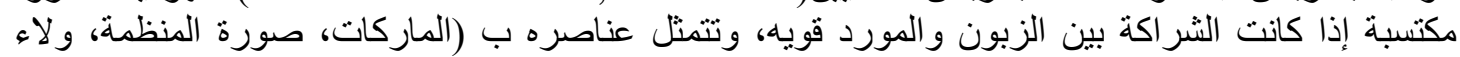

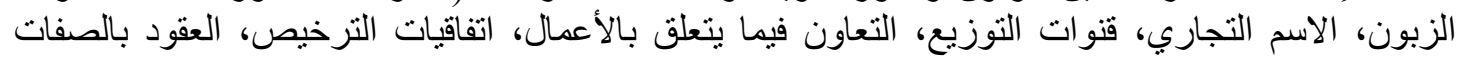

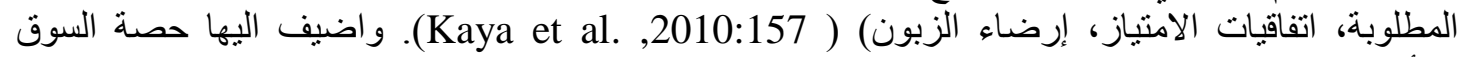
و الأرباح المحقة لكل زبون ومعدل الاحتفاظ بالزباءئن( 


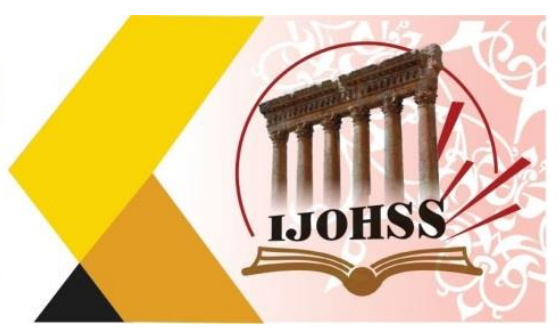

دـ مفهوم الابداع التقتي واهميته ودوافعه:

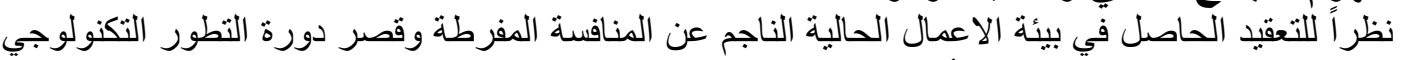

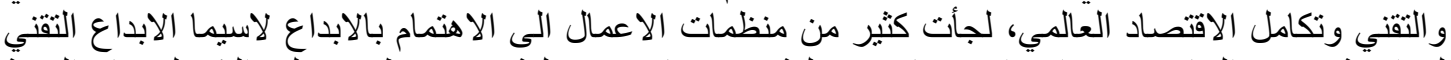

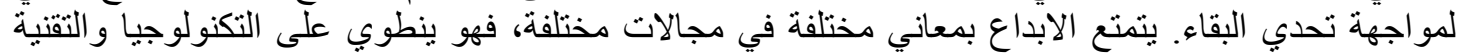

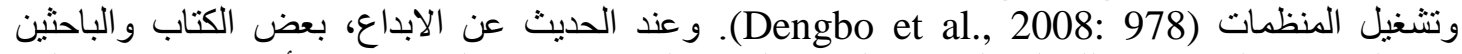

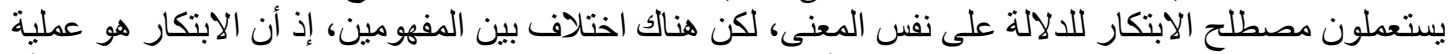

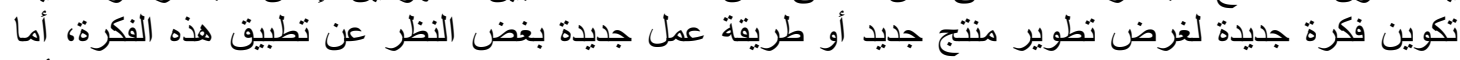

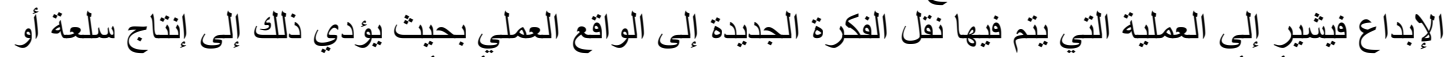

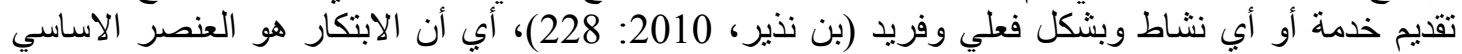

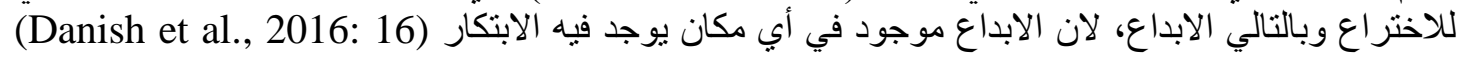

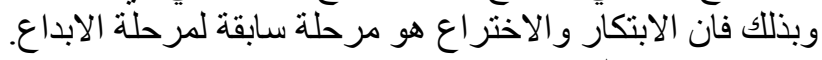

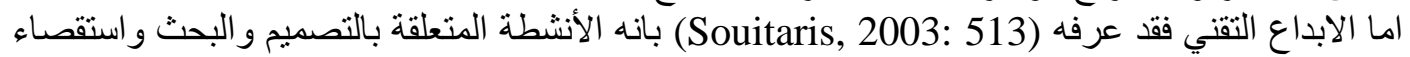

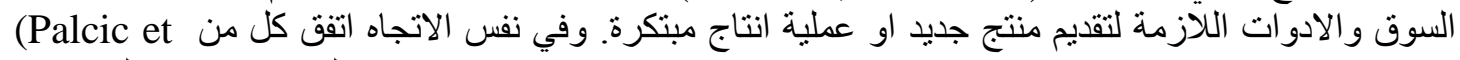

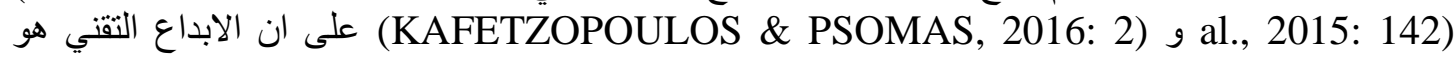
اعتماد فكرة جديدة تتعلق بمنتج جديد او ادخال عناصر جديدة في عمليات الانتاج تؤثر على الألى النظام التّفني

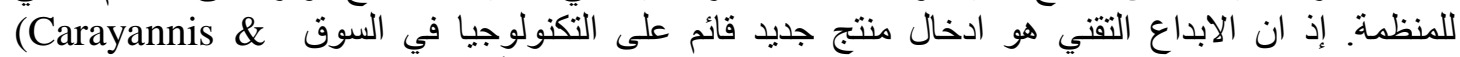

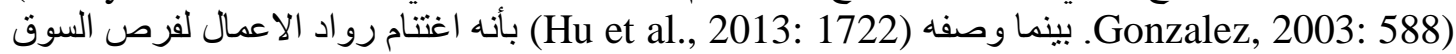

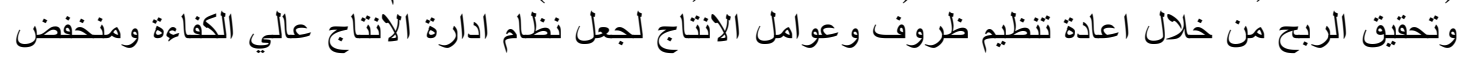

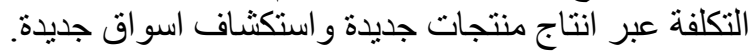

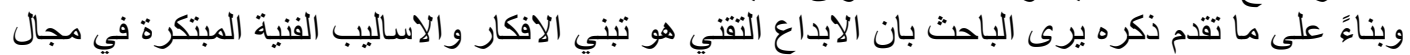

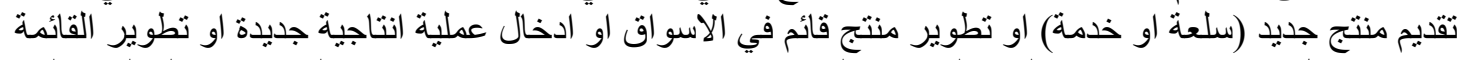

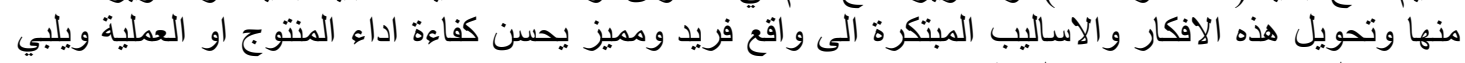

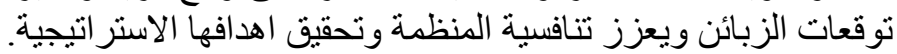

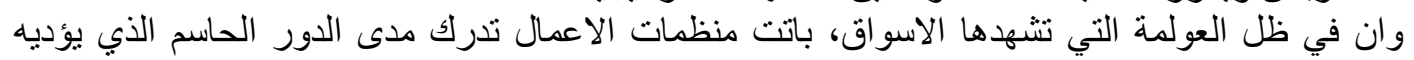

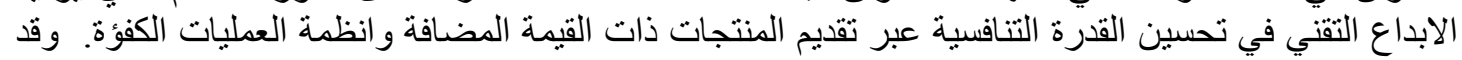

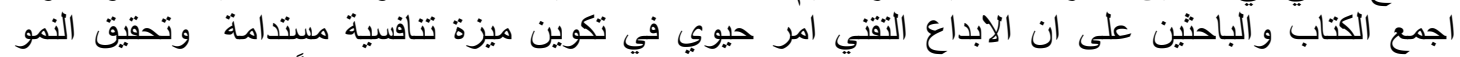

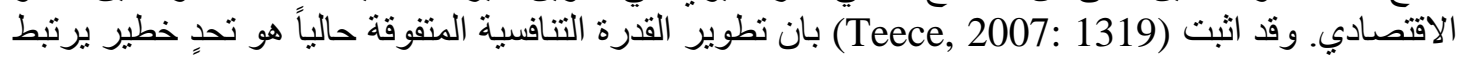

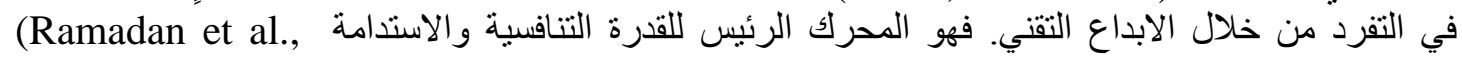

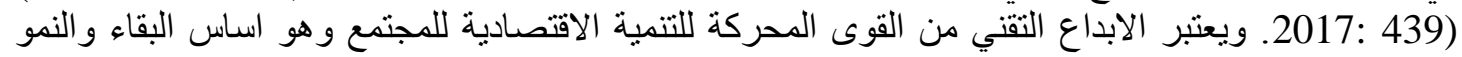

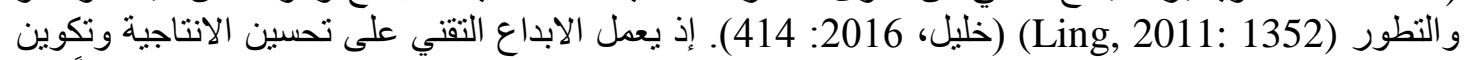

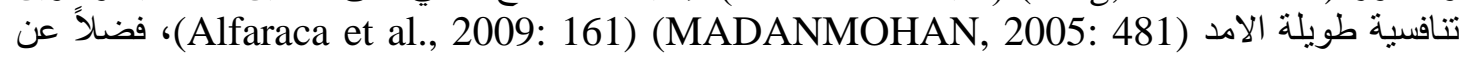
توفير وقت الانتاج ونوفير الإند التكاليف من خلال الابداع في العملية وتحسين المنفعة الاقتصادية والاستجابة

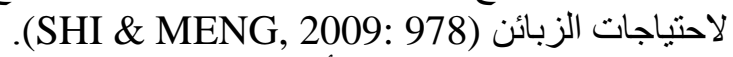

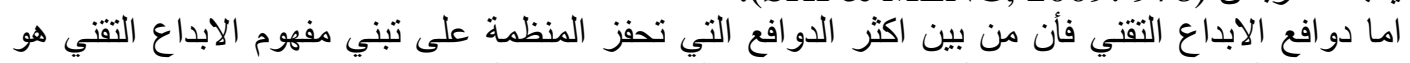

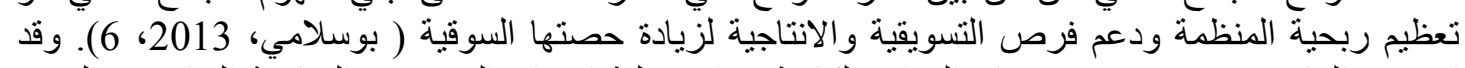

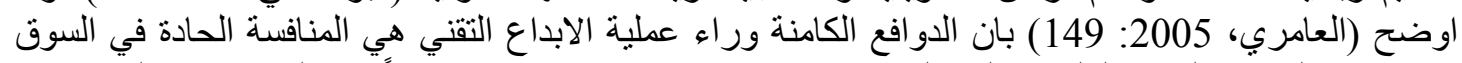

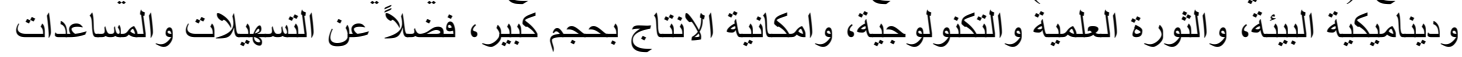

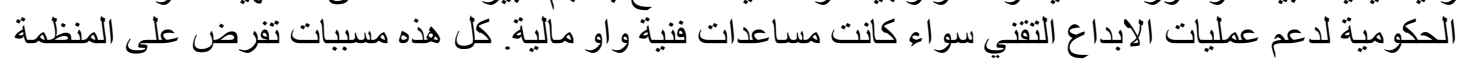

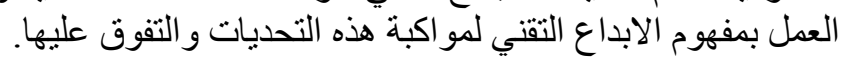

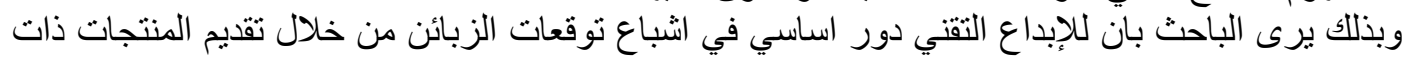

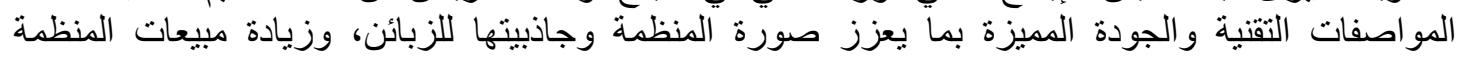




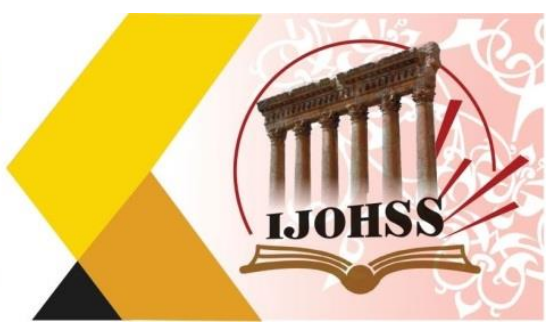

وربحيتها. فضلاً عن الدور الابداع التقني في تطوير اجزةة ووسائل العملية الانتاجية والمواصفات الفنية لها بما

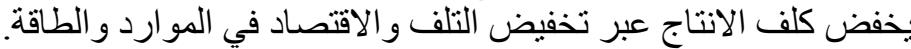

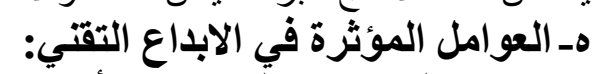

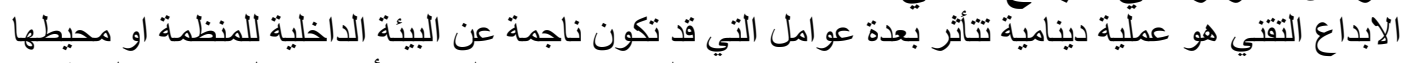

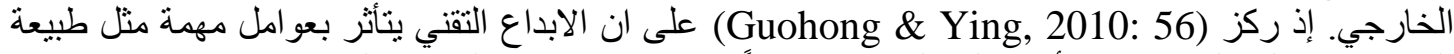

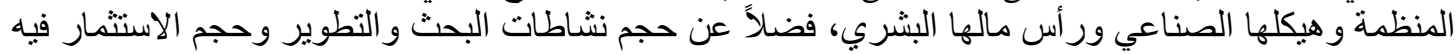

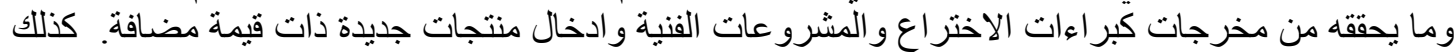

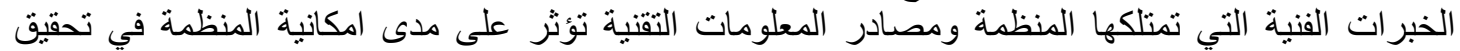

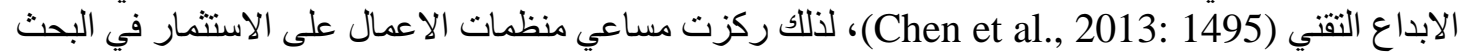

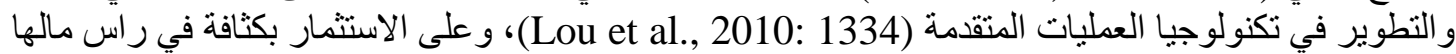
الفكري لدوره الرئيس في تحقيق الابداع التقني و الميزة التنافسية المستدامة (1) : (Al.Jinini et al., 2019).

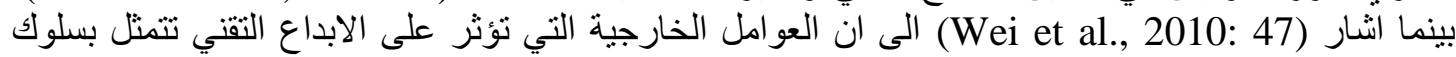

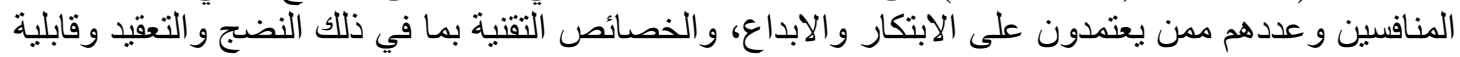

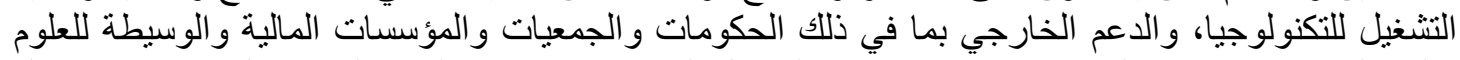

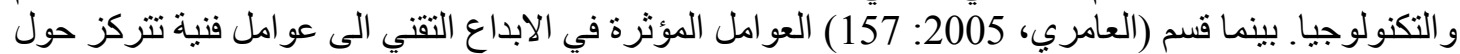

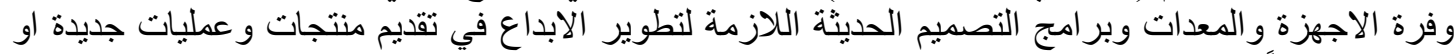

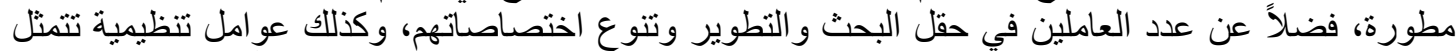

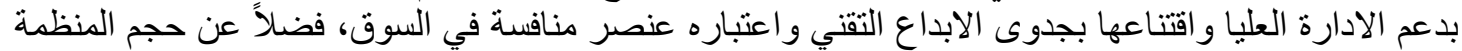

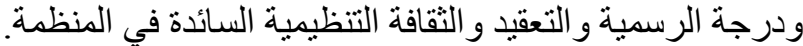

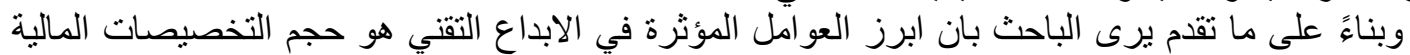

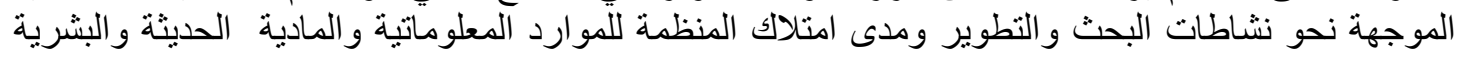

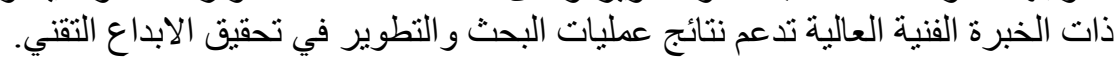

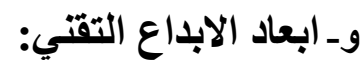

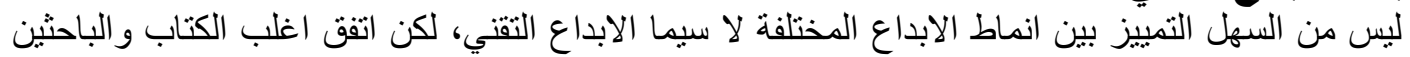

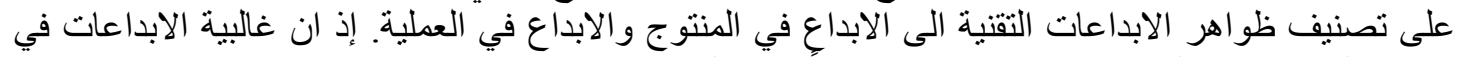

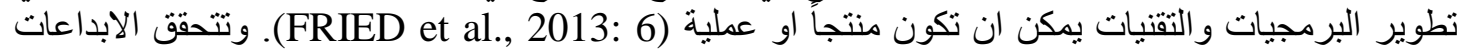

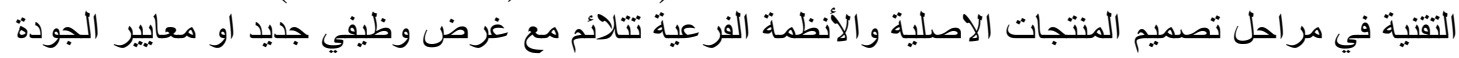

.(Koleva \& Toteva-Lyutova, 2018: 924)

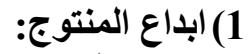
يعتبر المنتوج اساس وجود المنظمة و المنافسة في الاسواق، ويتمثل ابداع المنتوج في ادخال سلعة او خدمة

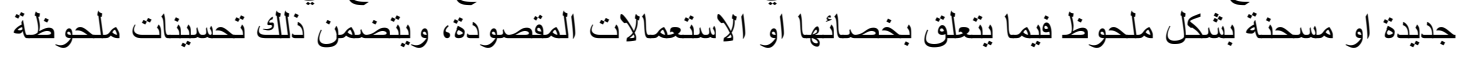

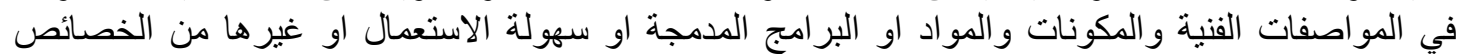

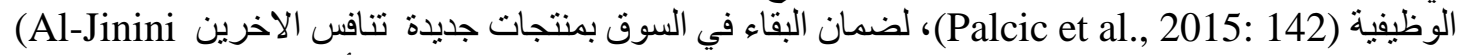

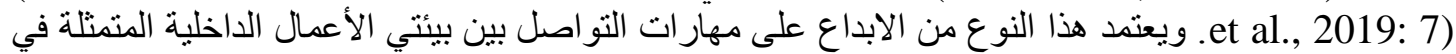

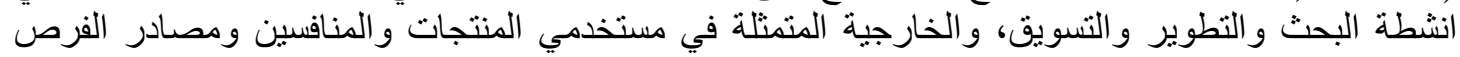

الجديدة (RAHMOUNI, 2011:14).

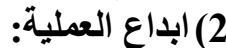

هو تنفيذ عطلية جديدة او محسنة بشكل كبير او طريقة تسليم، ويتضمن هذا تغييرات كبيرة في التقنيات

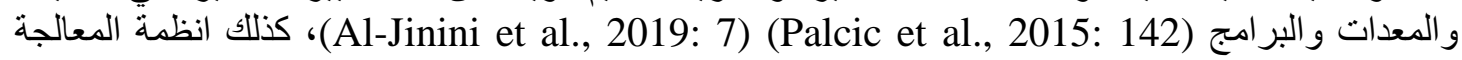
وعمليات الانتاج والادوات (Valence, 2010: 56)، من اجل تبسيط عمليات الانتاج وتخفيض التكاليف 
العدد (16) أكتوبر 2020

Volume (16) October 2020

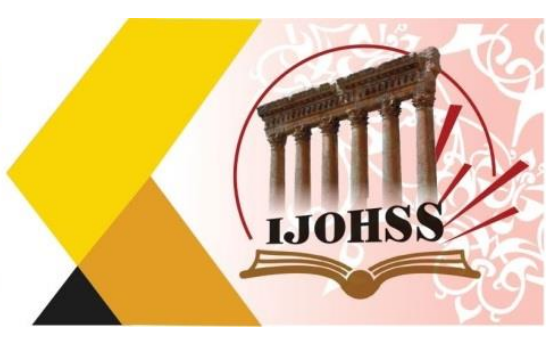

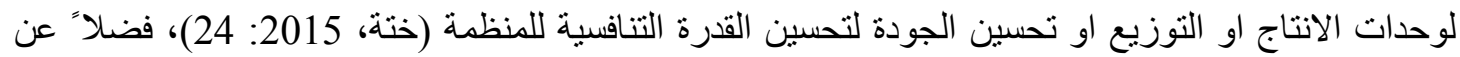

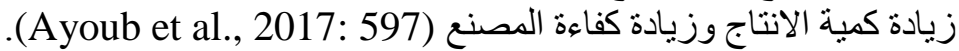

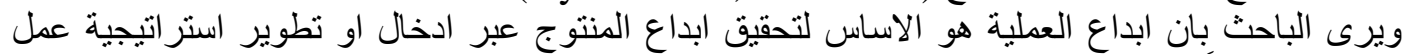

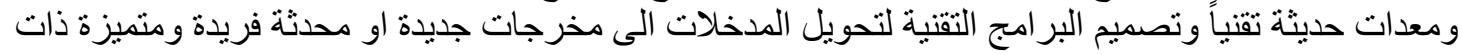

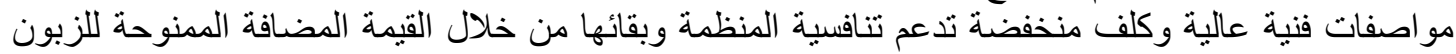

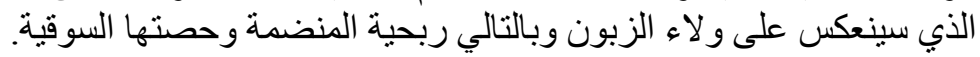

2. بعض من الار اسات السابقه الزبات

أ- (Inkinen et al,2017)

كان الهدف من هذه الدراسة هو فحص كيفية ارتباط تكوينات راس المال الفكري وممارسات ادارة المعرفة

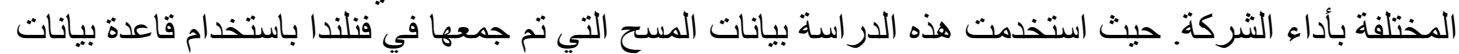

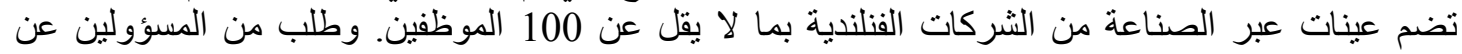

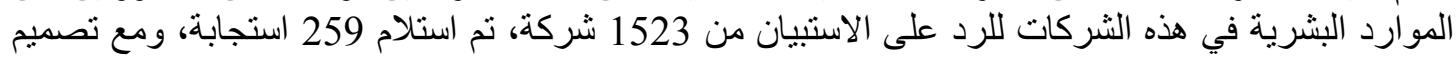

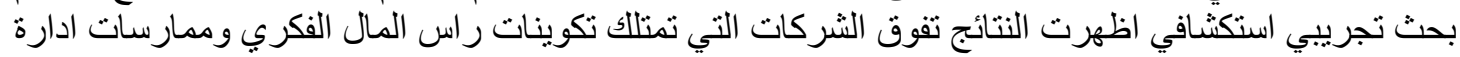

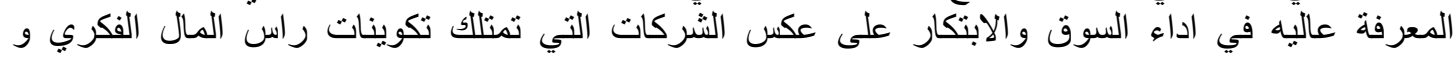
ممارسات ادارة المعرفة بشكل منخفض.

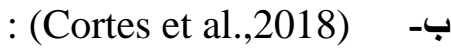

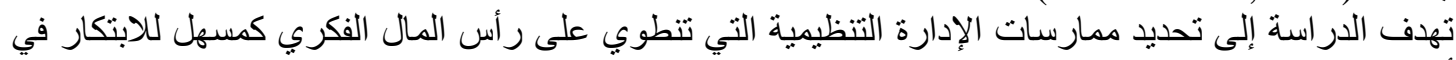

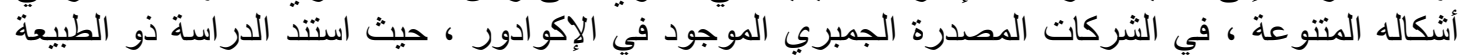

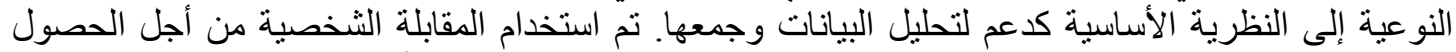

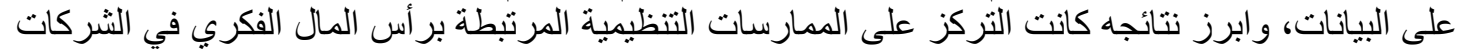

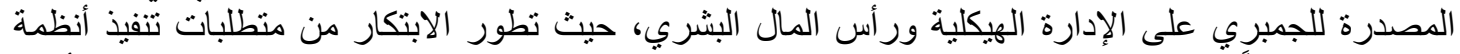

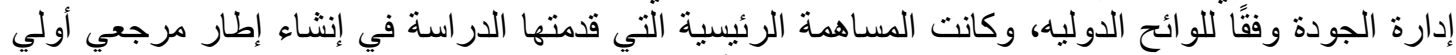

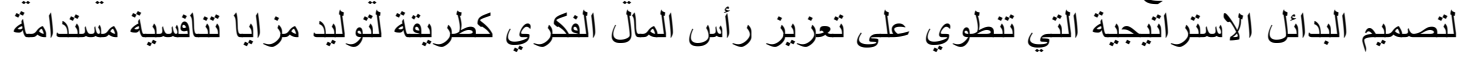

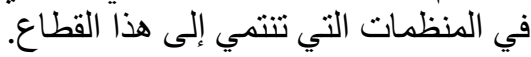

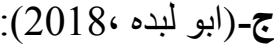

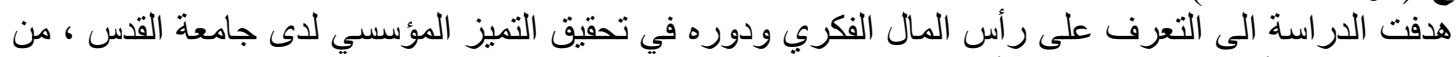

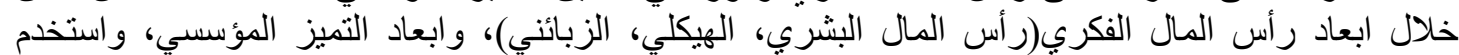

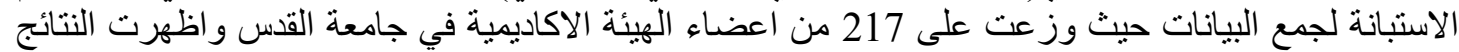

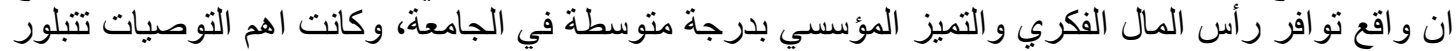

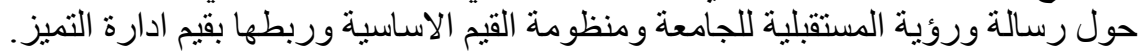

دا

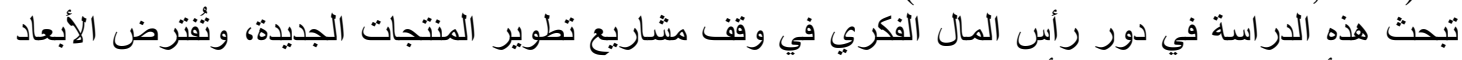

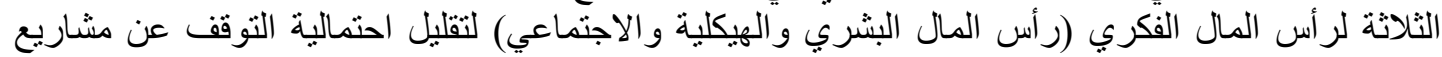

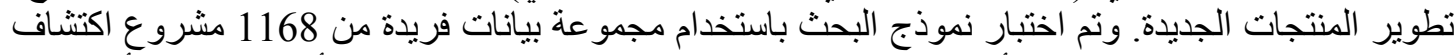

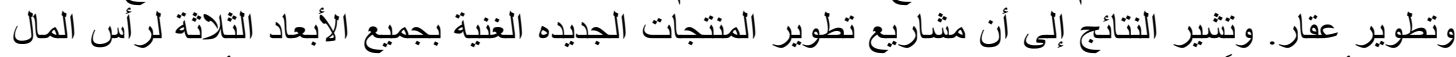

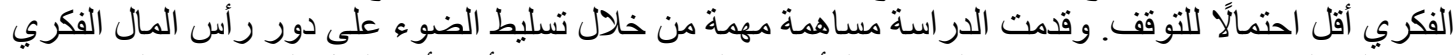

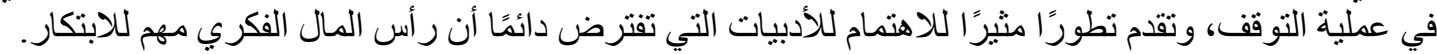
ه

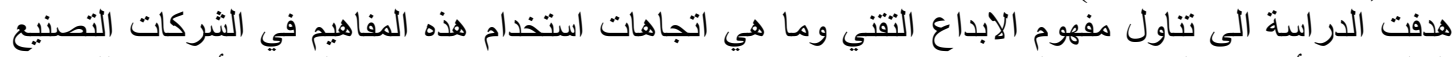

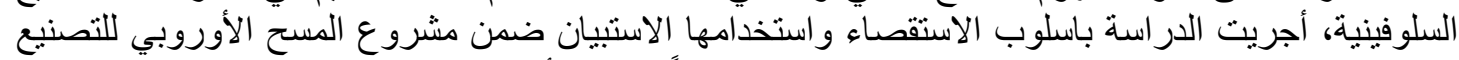

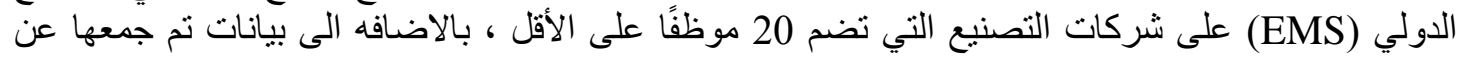




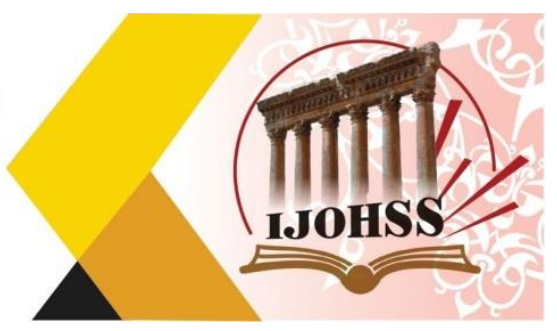

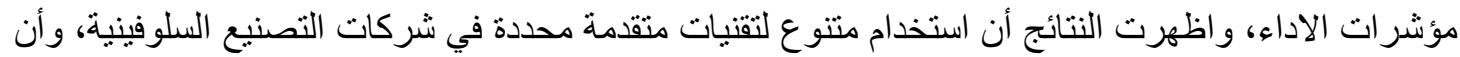
الاتجاهات في استخدام التقنيات المختارة في شركات التصنيع السلوفينية إيجابيه على الرغم من عدم استخدام الطفيف لتقنيات متقدمة معينة. و- در اسة (خليل، 2016):

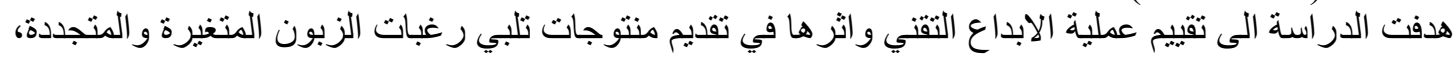

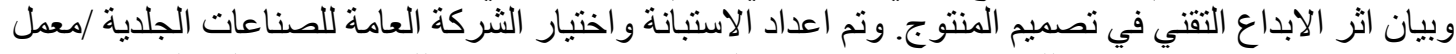

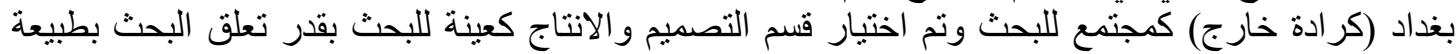

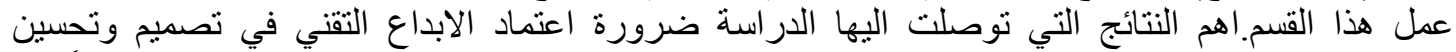

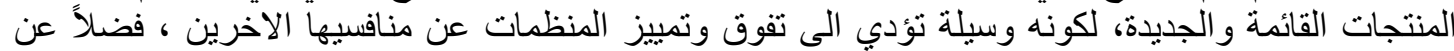

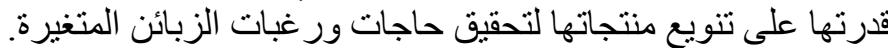
زم- در اسة (Al-Jinini et al., 2019)

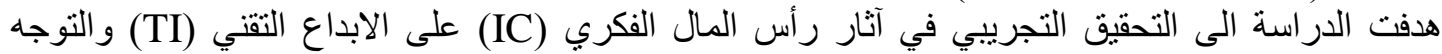

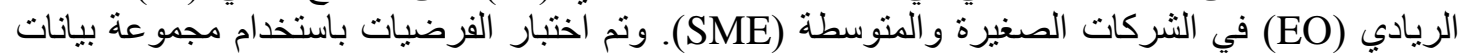

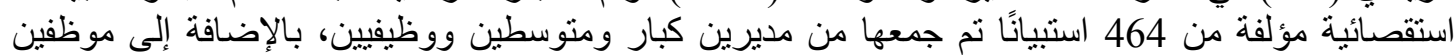

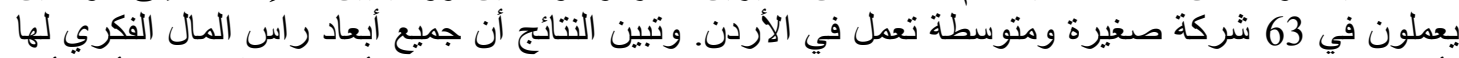

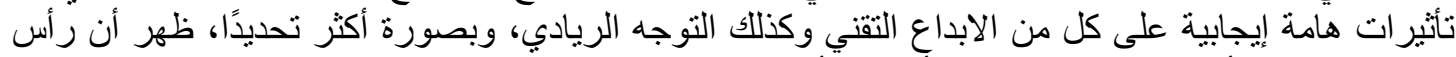

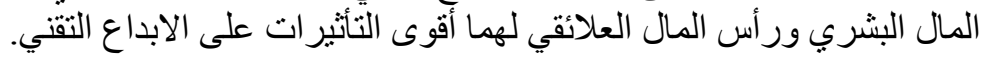

\section{• ما يميز الاراسة الحالية عن الاراسات السابقة:}

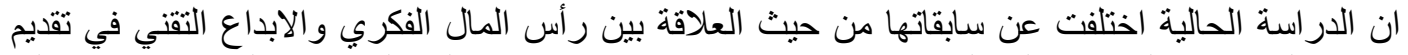

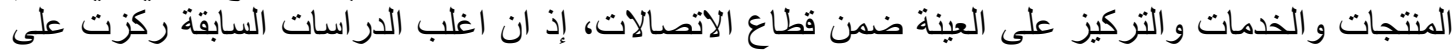

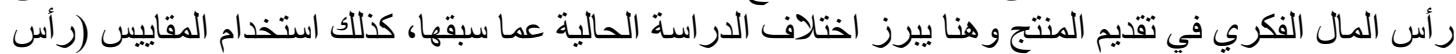
المال البشري ور أس ألمال الهيكلي ور أس المال الزبائني) لتحديد رأس المال الفكري للشركة المبحوثة.

\section{ثناثثا: منهجية واجراعات الاراسة:

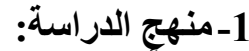

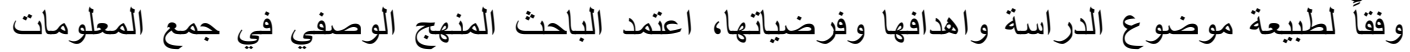

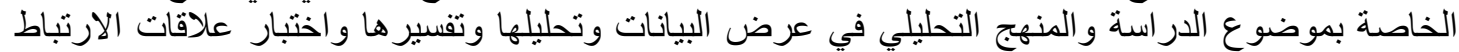

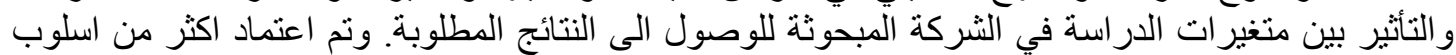

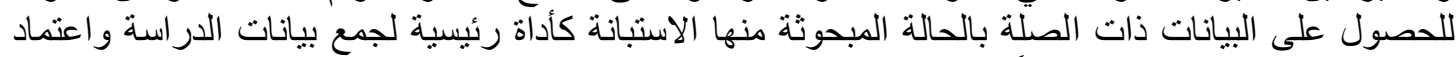

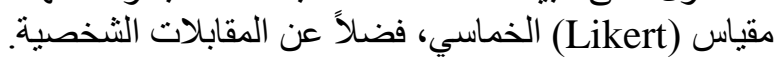

2-قياس صدق وثبات الاداة:

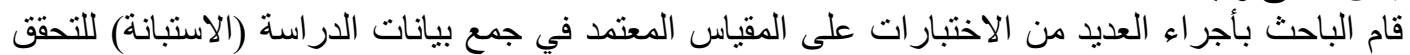

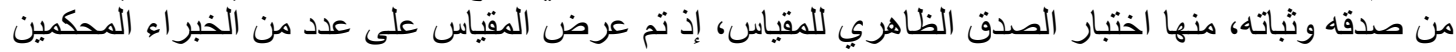

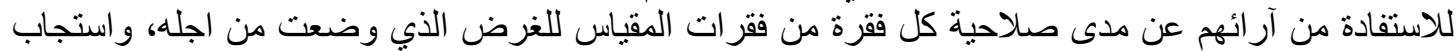

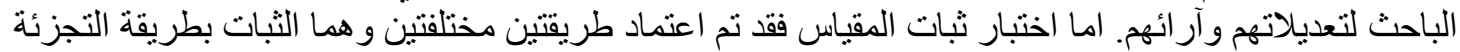

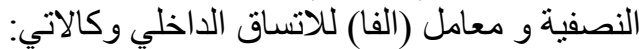

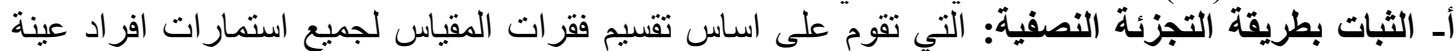

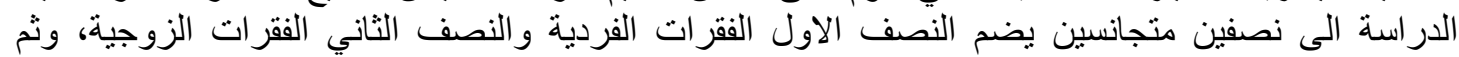




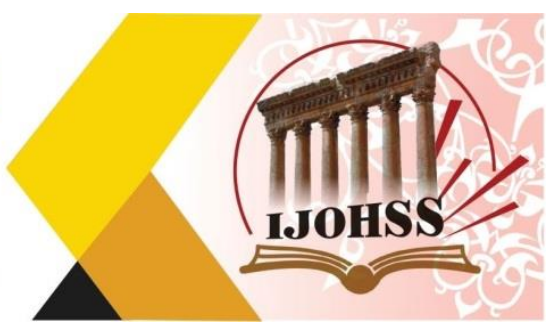

استخر اج معامل ارتباط بيرسون بين درجات النصفين فبلغ (0.904)، وبعد استعمال معادلة سبيرمان التصحيحية

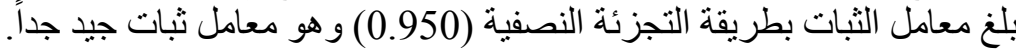

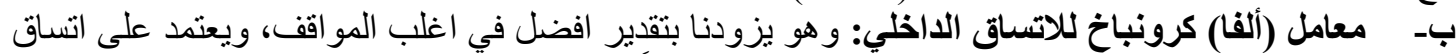

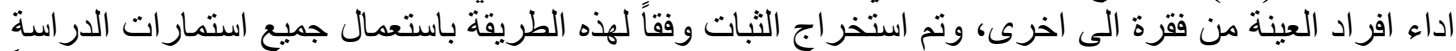

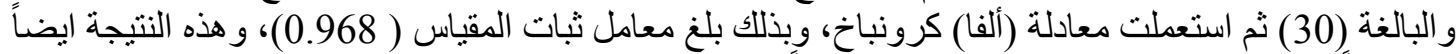
جيدة جداً تدل على ان المقياس منسق ومنسجم داخلياً.

3- الاساليب الاحصائية المستعملة في تحليل البيانات:

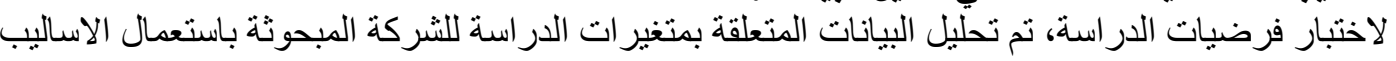
الاحصائية في البرنامج الاحصائي SPSS V23 لمعالجة البيانات و استخر اج النتائج وكالاتي:

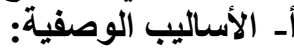
> الوسط الحسابي: لتحديد مستوى اجابات عينة الدر اسة لمتغير ات الدئة الدر اسة.

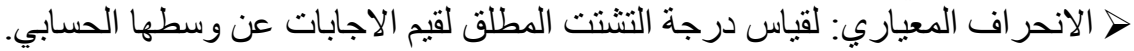

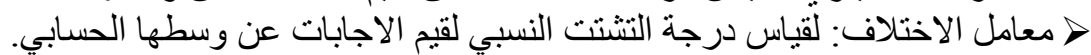

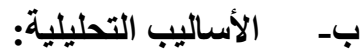
ه التجزئة النصفية ومعامل ألفا كرونباخ: لحساب ثبات العات المقياس و الاتساق الداخلي لفقر اته

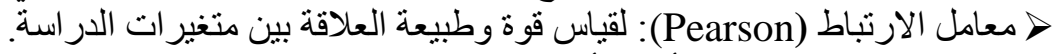

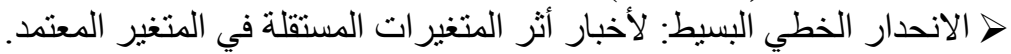

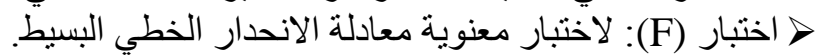

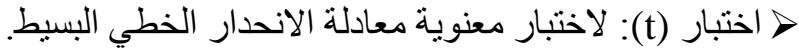

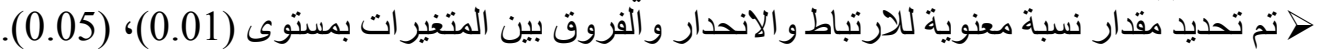

\section{رابعاً: عرض ومناقشة نتائج الدراسة}

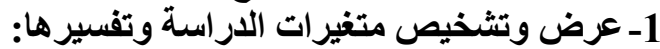

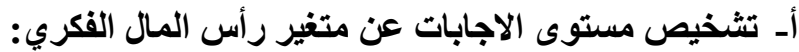
يوضح الجدول (1) مستوى اجابات افر اد عينة الدر استة عن متغير رأس الس المال الفكري للشركة المبحوثة.

جدول (1) مستوى اجابات عينة الدراسة عن متغير رأس المال الفكري

\begin{tabular}{|c|c|c|c|}
\hline المعياري & الحسابي & \multicolumn{2}{|l|}{ أ- رأس المال البشري } \\
\hline 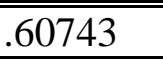 & 4.1000 & يتمتع الموظفون في شركتنا بمهاره عاليه. & 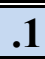 \\
\hline 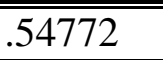 & 4.1000 & يمتلالك الموظفون في شركتنا خبره طويله في مجال عملهم. & $\overline{.2}$ \\
\hline 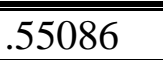 & 4.2000 & يسنطيع الموظفون في شركتنا على توليد افكار جديده. & 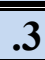 \\
\hline (269149 & 4.0667 & تجردص عاليه. تُنتا على مشاركة افر ادها في دور ات تدريبيه لزيادة معار فهم وتنفيذ العمل & .4 \\
\hline .64772 & 3.8333 & يستطيع الموظفون في شركتنا على ايجاد حلول بسبطه لمشاكل معقده. & 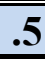 \\
\hline 0.4271 & 4.0600 & الاجمالي & \\
\hline الالمعياري & الحسابي & 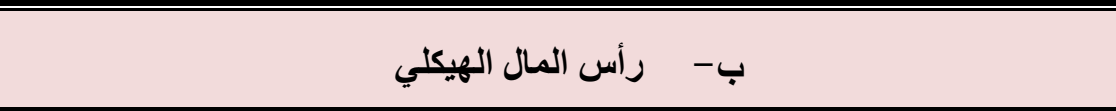 & \\
\hline
\end{tabular}




\section{المجلة اللدولية اللملوم الأسانية والإمتصاعية}

International Journal of Humanities and Social Sciences website:www.ijohss.com Email:editor@ijohss.com العدد (16) أكتوبر 2020 ISSN: $2415-4822$

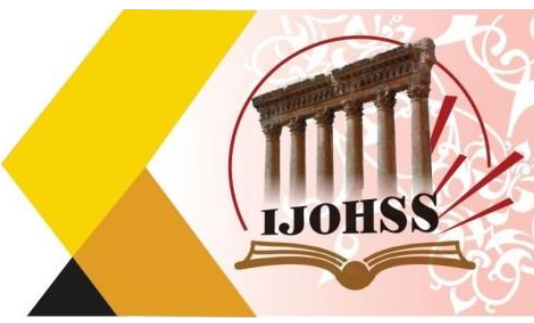

\begin{tabular}{|c|c|c|c|}
\hline .58329 & 4.0667 & المتللك شركتنا انظمة معلومات فعاله وحديثه تساهم في سرعة انجاز العمل بالثكل & .6 \\
\hline .64772 & 4.1667 & تحمي شركتنا المعرفه و المعلومات الاساسيه لتجنب خسارتها. & .7 \\
\hline $\bar{c} .71840$ & 3.9667 & تين الرؤس شركتناء هيكل التنظيمي الذي يؤسر درجات كبيره من الوضوح في العلاقات القائمة & .8 \\
\hline 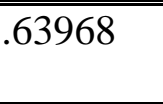 & 4.0667 & لاداء العمل. شركتا على تزويد الموظفين بكافة التجهيز ات الخاصهه بانظمة المعلومات للازمه & .9 \\
\hline .71840 & 4.0333 & نظم و اجر اءات شركتنا في مجال انظمة المعلومات تدعم الافكار الجديده. & .10 \\
\hline 0.5283 & 4.0600 & الاجمالي & \\
\hline المعياري & الوسابي & رأس المال الزبائني & \\
\hline .60648 & 4.3333 & تسعى شركتنا لتحقيق رضا وو لاء الزبائن و الحفاط على علاقات جيده معهم. & .11 \\
\hline 60743 & 4.1000 & تهتم شركتنا بعلاقاتها مع الموردين وتمتلك قاعدة بيانات عنهم. & 12 \\
\hline .69149 & 4.2667 & تهنم شركتنا بدر اسة تغير ات البيئة التنافسية لتبقى مو اكبة لتطور اتها. & .13 \\
\hline 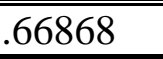 & 4.0333 & تسعى شر كتنا على تقديم خدمات ذات قيمة مضافه لزبائنها. & .14 \\
\hline .76489 & 3.9667 & تدرك شركتنا جيدا لاحتباجات زبائنها & .15 \\
\hline 0.5256 & 4.1400 & الاجمالي & \\
\hline 0.5282 & 4.0600 & اجمالي المتغير & \\
\hline
\end{tabular}

المصدر: اعداد الباحث اعتماداً على نتائج برنامج الميفير

من خلال الجدول (1) ينبين ان قيمة الوسط الحسابي لإجمالي متغير رأس المال الفكري للثركة المبحوثة المانة

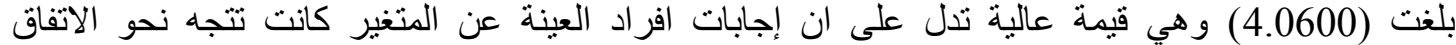

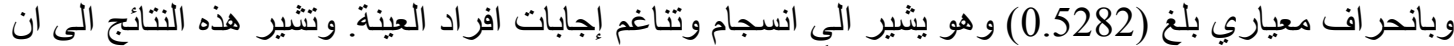

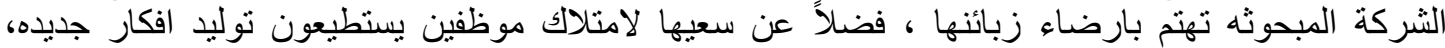

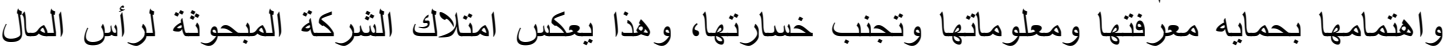
الفكري. و الجدول (2) يلخص المتوسطات الحسابية والانحر افات ومعامل الاختلاف و الاهمية النسبية لأبعاد متغير

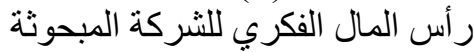
جدول (2) ابعاد متغير رأس المال الفكري لعينة الدراسة على وفق الوسط الحسابي والانحراف المعياري ومعامل الاختلاف و الاهمية النسبية العية الوبية

\begin{tabular}{|c|c|c|c|c|c|}
\hline الاهمية النسبية & معامل الاختلاف & الانحر اف المعياري & الوسط الحسابي & البعد & $ت$ \\
\hline 1 & 10.51 & 0.4271 & 4.0600 & رأس المال البشري & .1 \\
\hline$\overline{\overline{3}}$ & 12.80 & 0.5283 & 4.0600 & رأس المال الهيكلي & $\bar{~} .2$ \\
\hline 2 & 12.56 & 0.5256 & 4.1400 & رأس المال الزبائني & .3 \\
\hline
\end{tabular}




\section{المجلة الحولية اللملوم الآسانسية والإمتصاعية}

International Journal of Humanities and Social Sciences website:www.ijohss.com Email:editor@ijohss.com العدد (16) أكتوبر 2020 ISSN: $2415-4822$

\section{Volume (16) October 2020}

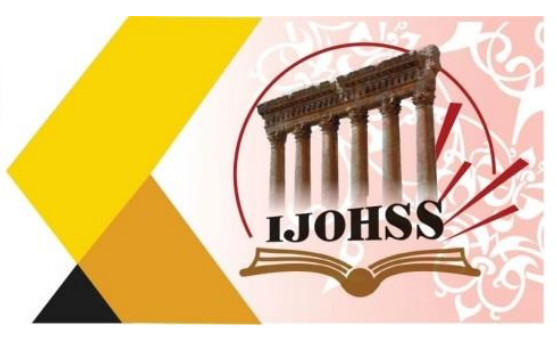

بناءً على النتائج في الجدول (2) جاء ترتيب بُعد (رأس المال البشري) في المرتبة الاولى مما يعني ان النيا

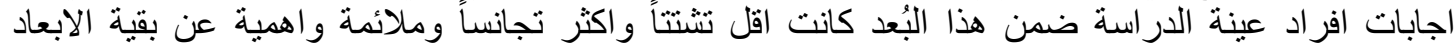

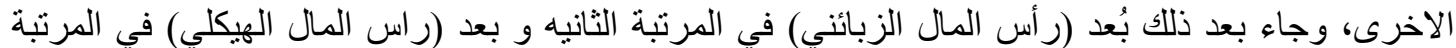

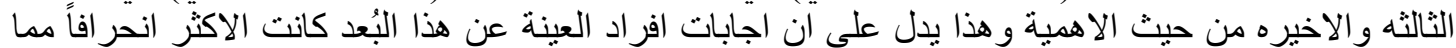

جدول (3) مستوى اجابات عينة الدراسة عن متغير الابداع التقتي

\begin{tabular}{|c|c|c|c|}
\hline المعياري & الوسط الوسي & \multicolumn{2}{|l|}{ أ- ابداع المنتوج } \\
\hline .61495 & 3.9667 & تعمل شركتنا على تقديم منتجات جديدة لم يَسبق إنتاجها بهدف كسب حصة سوقية إضافية & .16 \\
\hline .83045 & 4.0000 & تتعاون شركتنا مع خبر ات و استشار ات خارجية من اجل تقديم منتجات جديدة. & .17 \\
\hline .71840 & 3.9667 & تعمل شركتنا على تطوير مُنتجاتها اعتماداً على در اسات السوق وتحديد حاجات ور غبات زبائنها & .18 \\
\hline 166176 & 3.9000 & ينت تطوير مُنتجات شركتنا بالاعتماد على الخبر ات و المهارات الموجودة في الثركة & .19 \\
\hline .74664 & 3.8333 & تُخصص شركتنا مبالغ جيدة لجهود البحث و التطوير لتطوير منتجاتها & .20 \\
\hline 169149 & 3.9333 & يتت التنسيق و التعاون بين أقسام الإنتاج و البحث و التطوير لتطوير منتجات الثركة & .21 \\
\hline 166868 & 3.9667 & تسعى الثركة الى تقديم منتجات ذات خصائص ومو اصفات ومنفعة منفردة لبس لها مثيل في الاسو اق. & .22 \\
\hline .68145 & 4.1333 & تلجأ الشركة الى استعمال تكنولوجيا جديدة في تطوير منتجاتها. & .23 \\
\hline 63968 & 4.0667 & تلجأ الثركة الى استعمال مكونات جديدة من اجل تحسين منتجاتها. & .24 \\
\hline .66176 & 3.9000 & تتبنكى الثركة الافكار المبتكرة في تقديم منتجات جديدة ومحسنة ذات قيمة مضافة مواصفات تقنية & \\
\hline $\mathbf{0 . 5 3 3 2}$ & 3.9667 & الاجمالي & \\
\hline المعياري & الوسطي & ب- ابداع العملية & \\
\hline .75886 & 3.9000 & تعمل شركتنا على تصميم عمليات جديدة في ضو ه مُتطلبات تصميم المنتج الجديد. & .26 \\
\hline .77608 & 3.8667 & تقوم شركتنا بتقديم عمليات انتاج جديدة لغرض إنتاج مُنتجات جديدة. & .27 \\
\hline .71840 & 4.0333 & تسعى شركتنا لتحسين العمليات الإنتاجية بالاعتماد على الإمكانبات و الخبر ات المُتّاحة في الثركة. & .28 \\
\hline .69893 & 4.1667 & تمساعدة شركاسوا إلى إتباع الأساليب العلمية و البر امج الجديدة في تصميم وتحسين العمليات الإنتاجية & \\
\hline .63968 & 4.0667 & يسعى المُهندسين المُتخصصين بالإنتاج الى تحسين العمليات الإنتاجية في الثركة. &. $\mathbf{3 0}$ \\
\hline .59596 & 4.3000 & تقوم الثركة بالتجديد و التحسين المستمرة للعمليات الانتاجية من اجل تحسين جودة منتجاتها. & .31 \\
\hline .77608 & 3.8667 & اسهمت الثركة بشكل كبير في تحسين العمليات الانتاجية من خلال نشاطات البحث و التطوير . & .32 \\
\hline .77608 & 4.1333 & التبنى الثركة النوعية. الانظمة الحاسوبية و التكنولوجيا الجديدة في تصميم وتحسين العمليات الانتاجية ومعدات & .33 \\
\hline
\end{tabular}




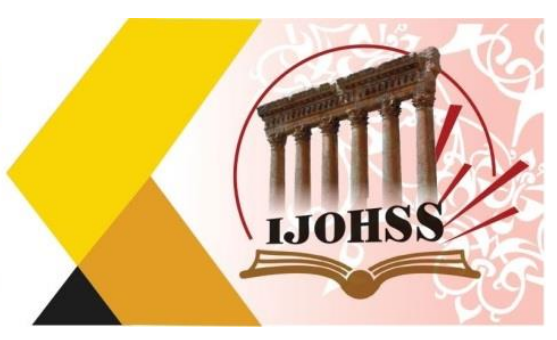

\begin{tabular}{|c|c|c|}
\hline .66176 & 4.1000 & تو استعمال الثركة عند تصميم عملية ما بتشكيل فريق عمل مزود بالمعلومات الكافية عن العملية الانتاجية \\
\hline .71197 & 4.1000 & تسعى الثركة الى تحسين عمليات الانتاج الخاصة بالأنشطة الداعمة كأنظمة الصيانة. \\
\hline 0.5673 & 4.0533 & الاجمالي \\
\hline 0.5254 & 4.0100 & اجمالي المتغير \\
\hline
\end{tabular}

المصدر: اعداد الباحث اعتمادأ على نتائج برنامج النئير

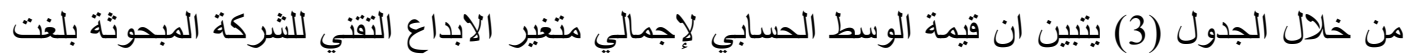

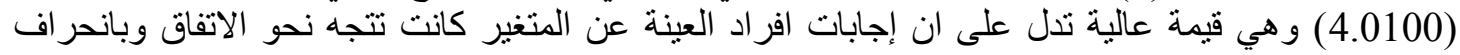

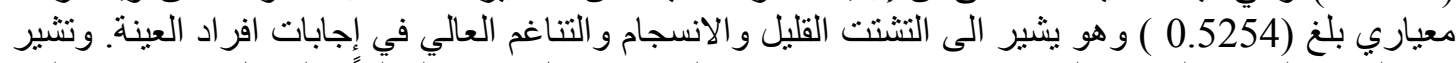

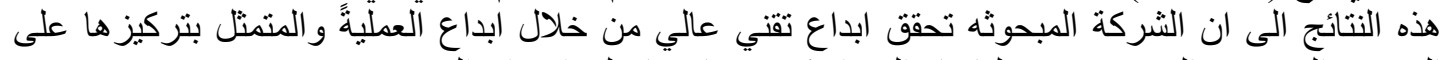

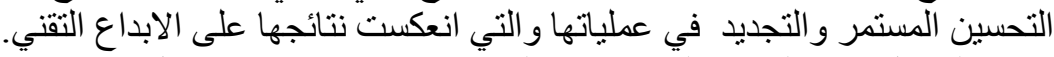

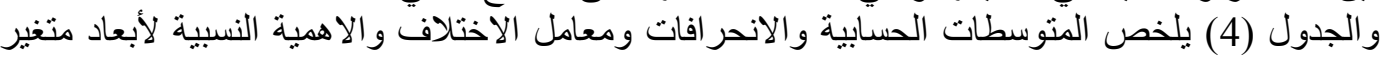

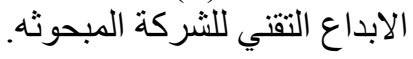

جدول (4) ابعاد متغير الابداع التقني لعينة الدراسة على وفق الوسط الحسابي والانحراف المعياري ومعامل الاختلاف والاهمية النسبية الإنية

\begin{tabular}{|c|c|c|c|c|c|}
\hline الاهمية النسبية & معامل الاختلاف & الالحياري & الوسط الحسابي & البعد & ت \\
\hline 1 & 13.441 & $\mathbf{0 . 5 3 3 2}$ & 3.9667 & ابداع المنتوج & .1 \\
\hline 2 & 13.996 & 0.5673 & 4.0533 & ابداع العملية & .2 \\
\hline
\end{tabular}

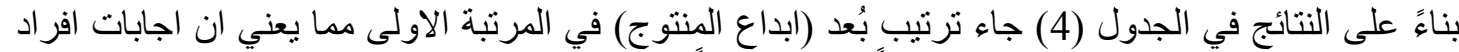

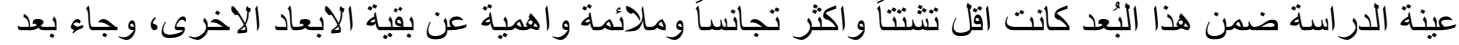

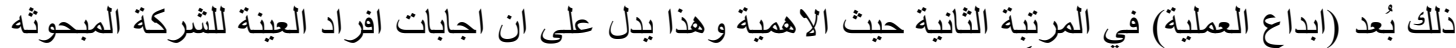
عن هذا البُعد كانت الاكثر أنحر افاً مما جعله الاندة الاقل الهمية. 2- ألتبار فرضيات الاراسة: أـ الارتباطات بين متغيرات الاتراسية الاراسة:

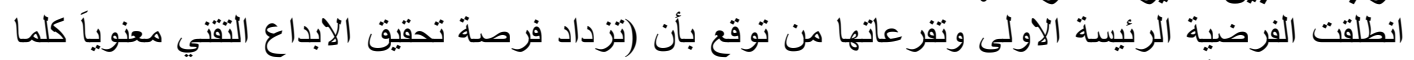

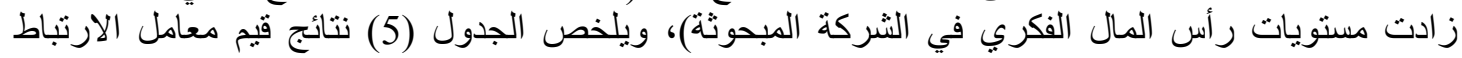
بين متغير ات الدر اسة للثركة المبحوثة النّة

جدول (5) قيم الارتباط بين متغيري رأس المال الفكري والابداع التقتي

\begin{tabular}{|c|c|c|c|c|}
\hline المال ألفكري رأس & رأس المبال & رأس المال & رأس المال & الفك s \\
\hline $0.877 * *$ & $0.864 * *$ & $0.849 * *$ & $0.524 * *$ & اجمالي الابداع التقني/ \\
\hline
\end{tabular}

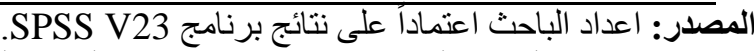

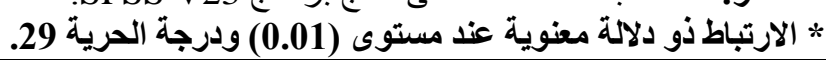




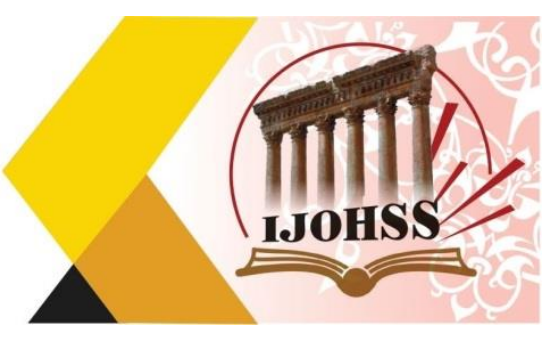

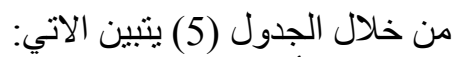

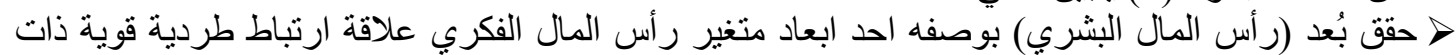

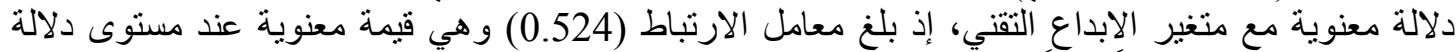

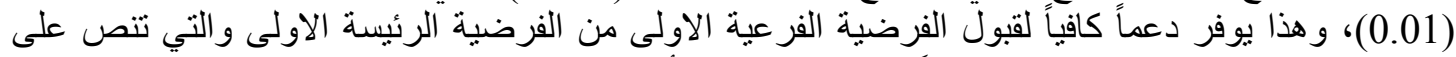

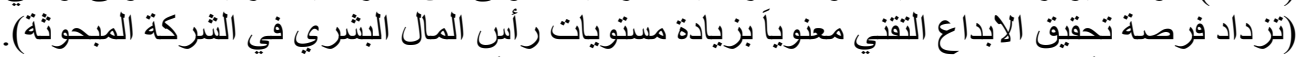

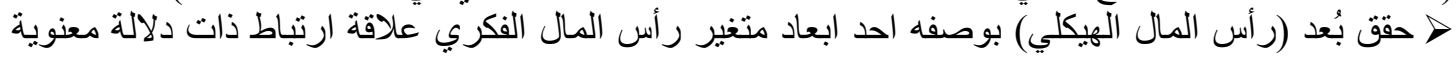

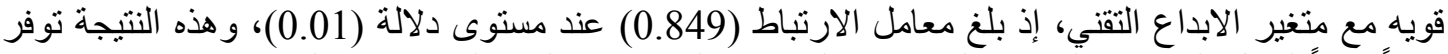

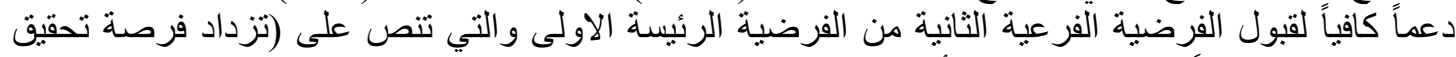

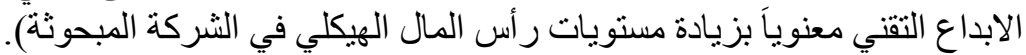

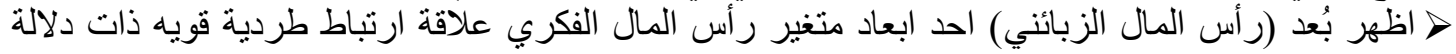

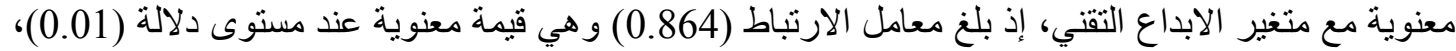

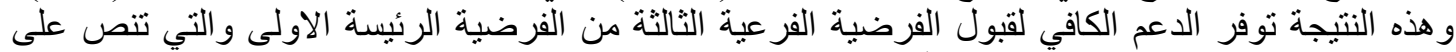

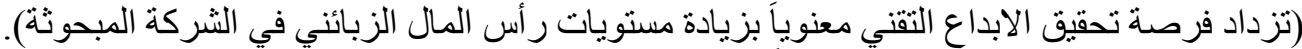

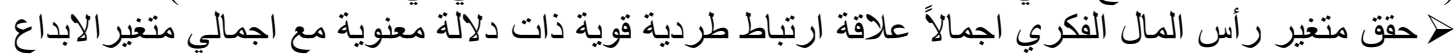

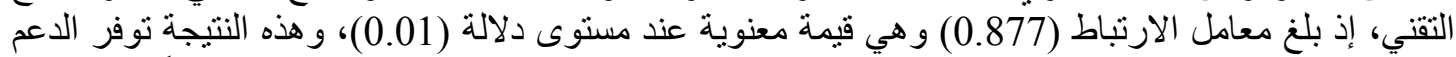

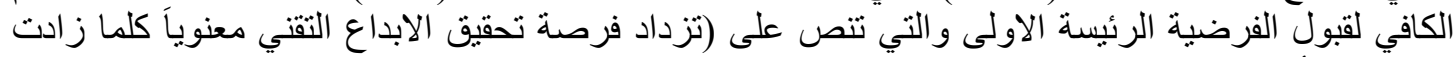

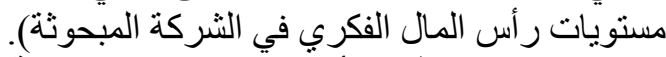

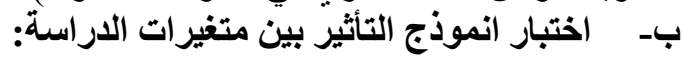

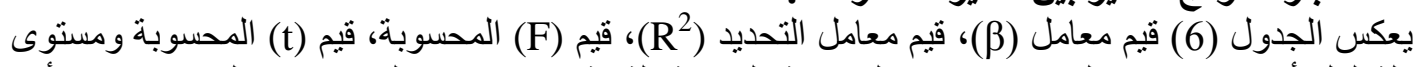

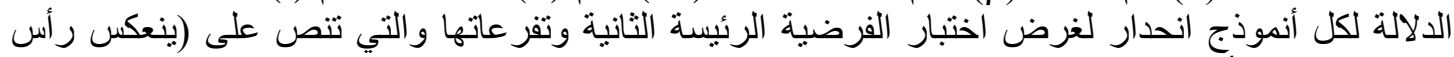

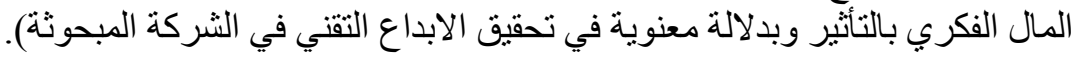

جدول (6) نتائج تأثير ابعاد متغير رأس المال الفكري في اجمالي ابعاد الابداع التقني باستعمال تحليل الاتحدار الخطي البسيط الفيال

\begin{tabular}{|c|c|c|c|c|c|c|c|}
\hline مستوى الدلالة & المحسيوبة & المحسوبة & قالتحدة معامل & معامل م & المعتمد & المتغير المستقل & ت \\
\hline 0.003 & 3.257 & 10.607 & 0.275 & 0.524 & \multirow{4}{*}{ الابداع التقني } & رأس المال البشري & .1 \\
\hline 0.000 & 8.494 & 72.141 & 0.720 & 0.849 & & رأس المال الهيكلي & .2 \\
\hline 0.000 & 9.069 & 82.245 & 0.746 & 0.864 & & رأس المال الزبائني & .3 \\
\hline 0.000 & 9.682 & 93.741 & 0.770 & 0.877 & & اجمالي رأس المال الفكري & .4 \\
\hline
\end{tabular}

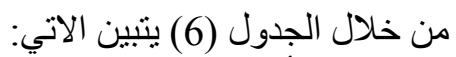

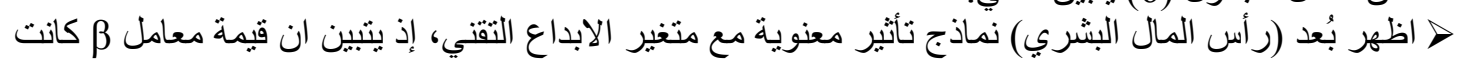

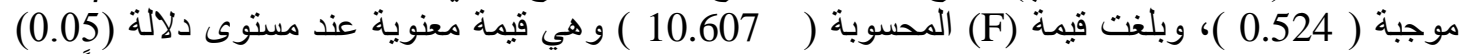

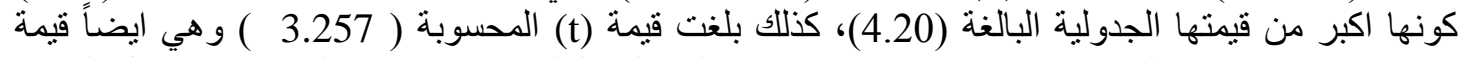

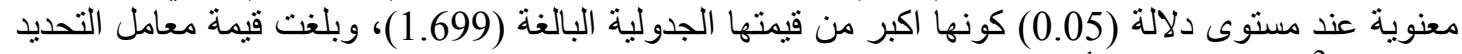
وتعني ان رأس المال البشري يفسر ( 27 (R2=0.275) 
العدد (16) أكتوبر 2020

Volume (16) October 2020

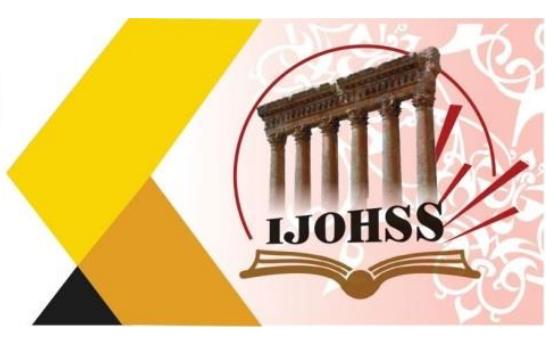

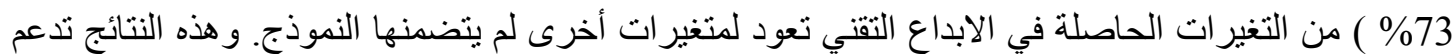

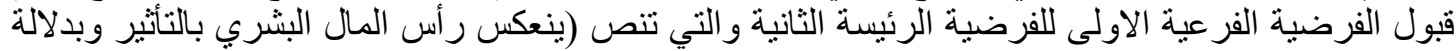

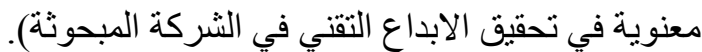

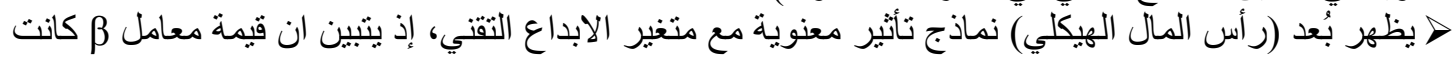

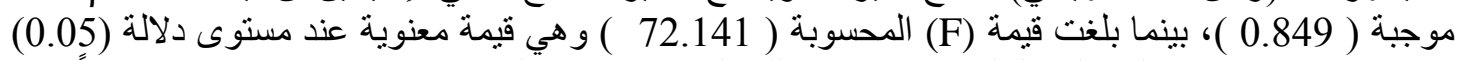

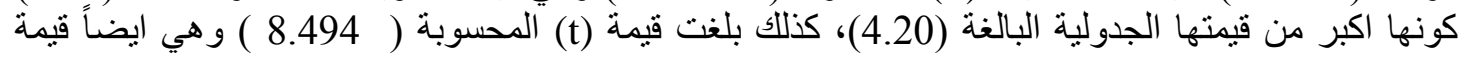

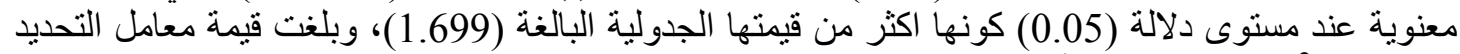
( R R $^{2}=0.720$ )

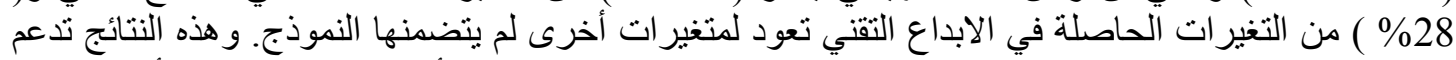

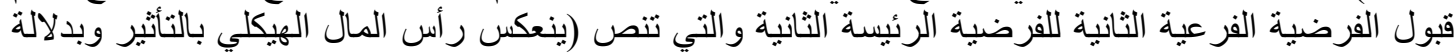
معنوية في تحقيق الابداع التقني في الثركة الثرانية المبحوثة).

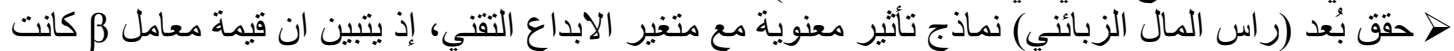

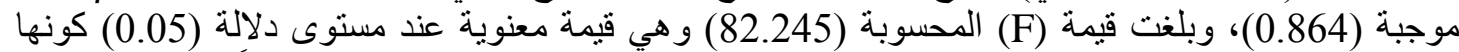

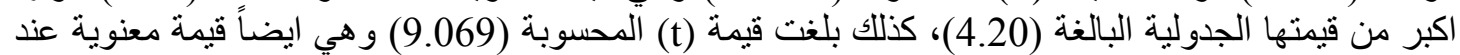

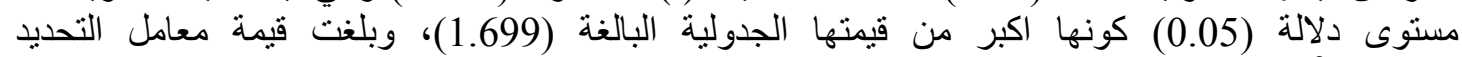

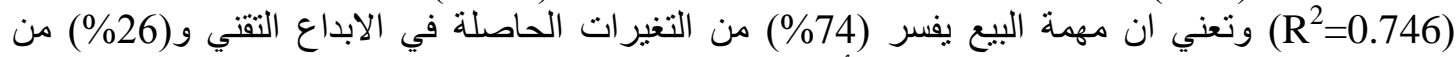

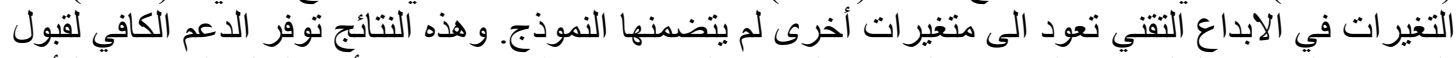

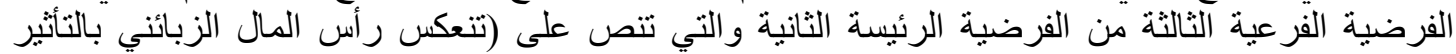

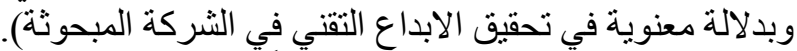

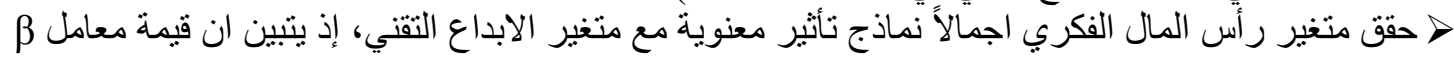

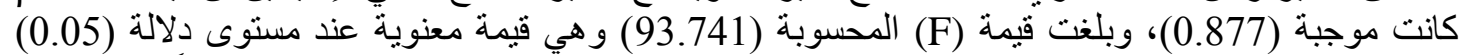

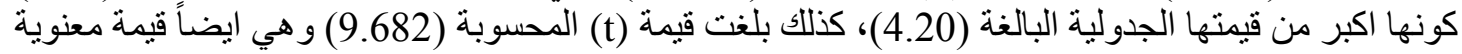

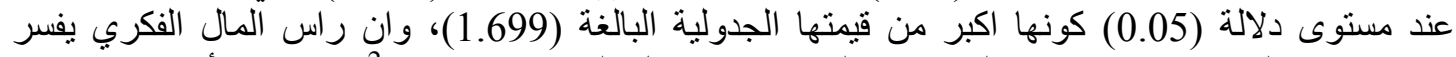

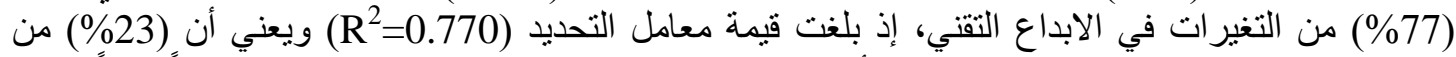

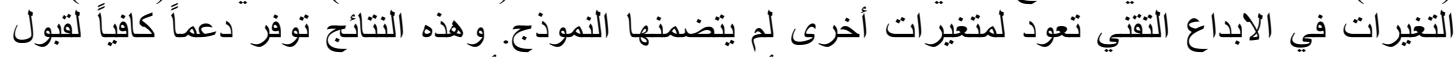

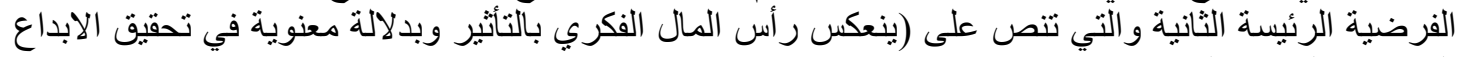
التقني في الثركة المبحوثة).

$$
\text { رأـ الاستتناجات: الاستتتاجات والتوصيات: }
$$

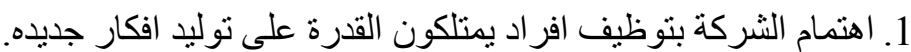

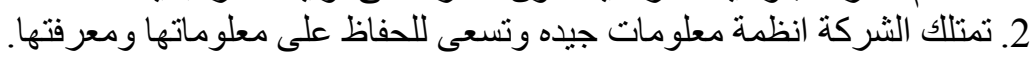

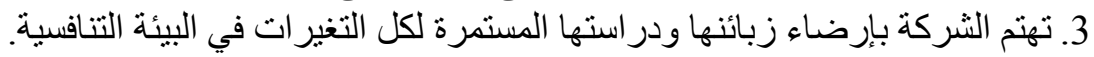

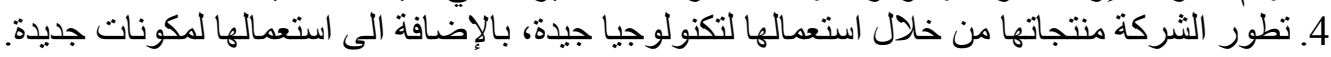

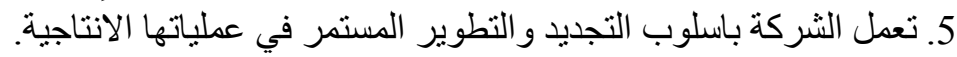
6. تعتمد الثركة اسلوب فرق العمل مزود بالمعلومات الكافية ، بالإضافة للأنظمة الحاسوبية الجديدة في تصميم عملياتها. 7. اظهر ا النتائج امتلاك الثركة لمكونات رأس المال الفكري بصوره جيده و الاخص لمكون راس المال المال البشري.

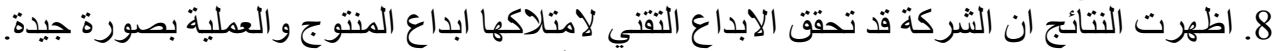

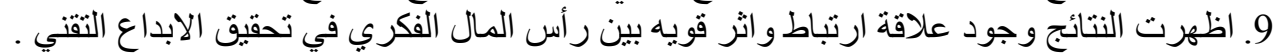




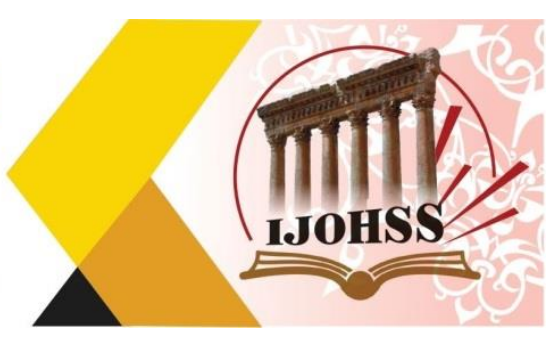

1. ض. التورة قيات الثركة بالاهتمام بصوره اكبر بقدر ات العاملين المتعلقة بإيجاد حلول للمشاكل المعقدة.

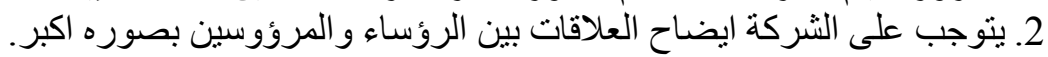

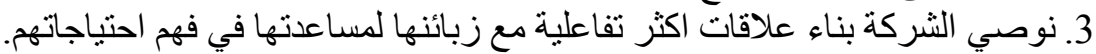

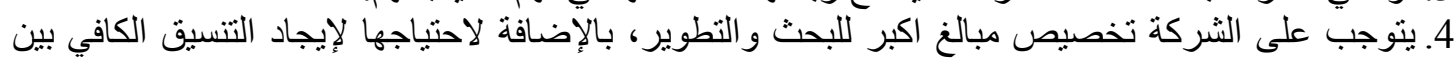
قسم الانتاج و البحث و التطوير. 5. بسبب عدم الهتمام الكافي من قبل الثركة بالبحث و التطوير فأنها لم تحسن عملياتها الانتاجية بالصورة الكافية

لذلك نوصيها بذلك.

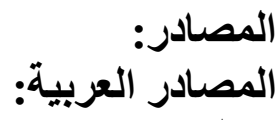

1. الربيعاوي، سعدون حمود جثير، عباس، حسين وليد حسين، 2015، رأس المال الفكري، عمان: دار غيداء

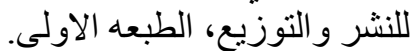

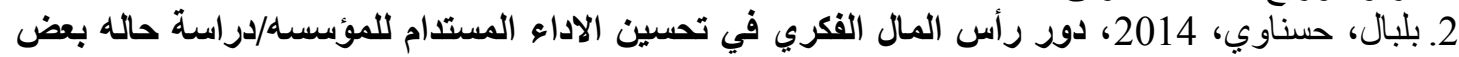

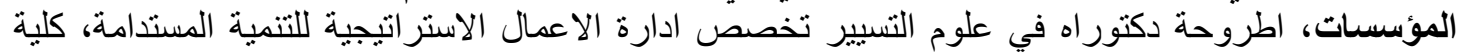

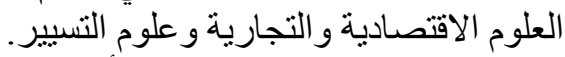

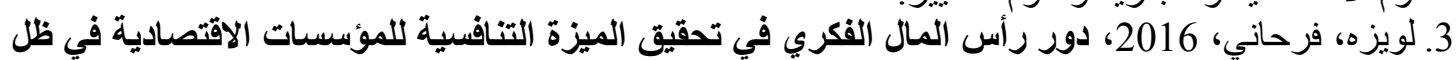

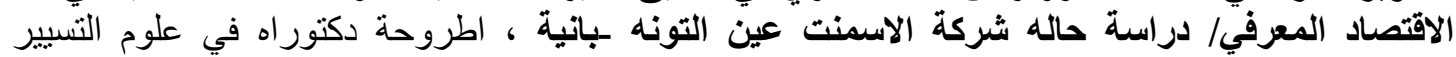

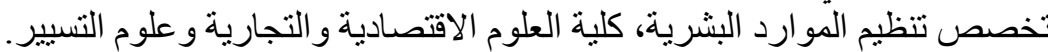

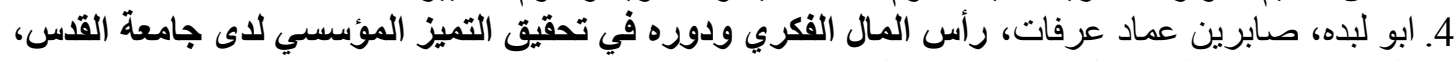

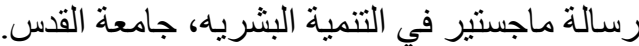
5. غياط، شريف، رجال، فير فيرو، 2011، رأس المال الفكري ودوره في اكساب المؤسسة ميزة تنافسية،

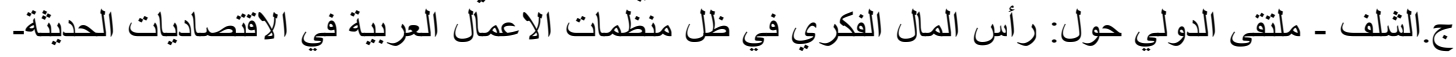

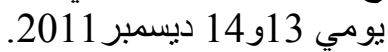
6. العامري، صالح مهدي محسن (2005)، "العوامل التكنولوجية والتنظيمية المؤثرة في الإبداع التكنولوجي: التوائية

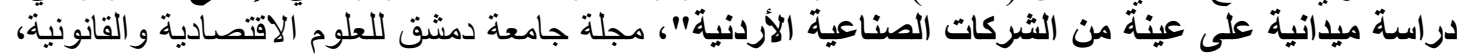

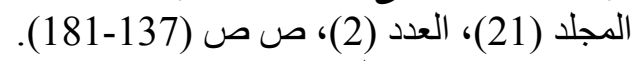

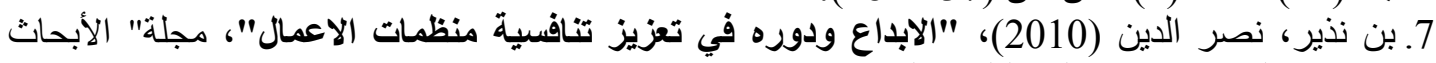

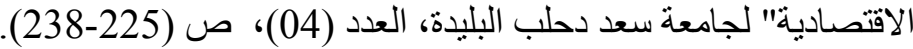

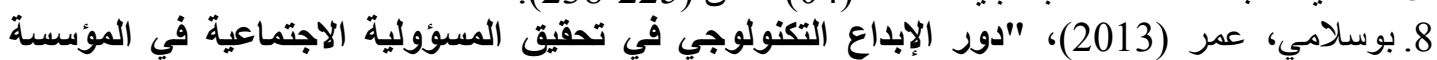

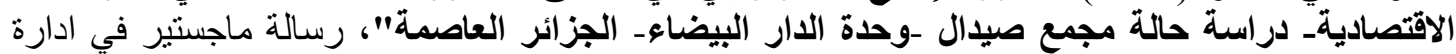

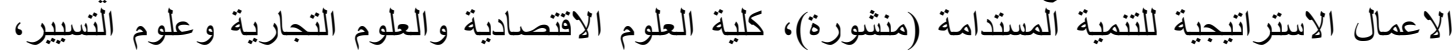
جامعة سطيف، الجز ائر. 9. ختة، مبروكة (2015)، "فعالية الإبداع التكنولوجي في تحسين تنافسية المؤسسة الاقتصاديةـ دارسة حالة التوائة

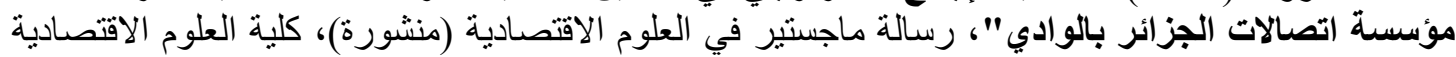

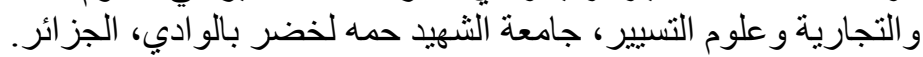

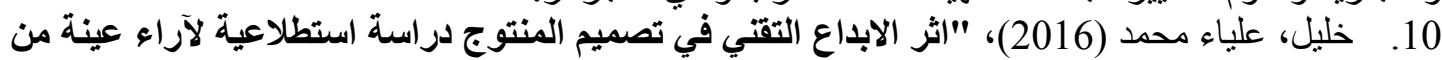

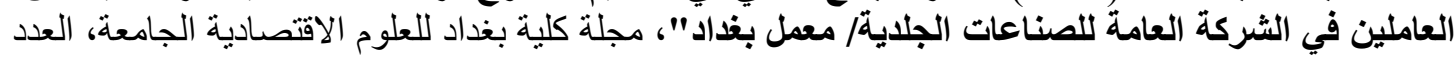

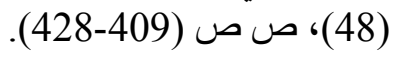




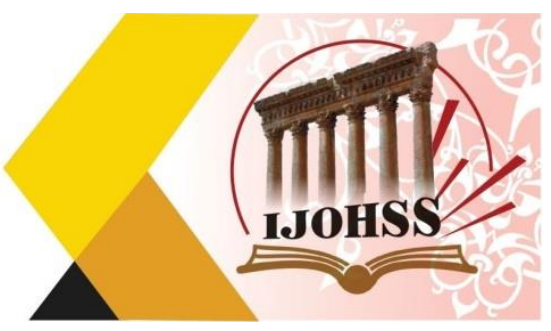

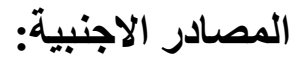

1. GOGANa, Luminita-Maria\& Rennungb, Frank\& Fistisc, Gabriela\& Draghicia, Anca, 2014, A proposed tool for managing intellectual capital in small and medium size enterprises , Procedia Technology 16 ( 2014 ) 728 - 736.

2. Isabel ,Sandra \& Bailoa, Rodrigues,2017, Intellectual capital: The strategi resource of organizations, The Małopolska School of Economics in Tarnów Research Papers Collection, vol. 36, iss. 4, December 2017.

3. Cortes, Enrique Claver \& Saez, Patrocinio Zaragoza- \& Gonzalez-Illescas ,Mayiya ,2014, Intellectual capital management: An approach to organizational practices in Ecuador, IC, 2018 - 14(2): 270-285.

4. Eva, Jelínková\& Milena, Jiřincová, 2015, Diversity Management as a Tool of Managing Intellectual Capital, Journal of Competitiveness,Vol. 7, Issue 4, pp. 3 17, December 2015.

5. Ognjanović, Jasmina,2016, INTELLECTUAL CAPITAL: CHARACTERISTICS AND SIGNIFICANCE IN THE SERVICE SECTOR , Vol. 62, july-september 2016, № 3.

6. ABHAYAWANSA, SUBHASH \& ALEKSANYAN, MARK \& BAHTSEVANOGLOU ,JOHN, 2015, The use of intellectual capital information by sell-side analysts in company valuation, Accounting and Business Research, 2015, Vol. 45, No. 3, 279-306.

7. Ferreira ,Aristides Isidoro \& Martinez ,Luís Fructuoso,2011, Intellectual Capital: Productivity and Investment Perceptions , RAC, Curitiba, v. 15, n. 2, art. 5, pp. 249-260, Mar./Abr. 2011

8. Inkinen, Henri \& Ritala, Paavo \& Vanhala ,Mika \& Kianto, Aino,2017, Intellectual capital, knowledge management practices and firm performance , Journal of Intellectual Capital ,Volume 18 Issue 4 .

9. Subramanian, Annapoornima M. \& Vrande, Vareska van de, 2019, The role of intellectual capital in new product development: Can it become a liability?, Volume65, Issue6 ,September 2019, Pages 517-535

10. Kaya, Funda Bahar \& Sahın, Gonca Guzel \& Gurson, Poyraz,2011, Intellectual capital in organizations, Problems and Perspectives in Management, Volume 8, Issue 1, 2010

11. Abdulaali, Aymen Raheem, 2018, THE IMPACT OF INTELLECTUAL CAPITAL ON

BUSINESS ORGANIZATION, Academy of Accounting and Financial Studies Journal Volume 22, Issue 6, 2018

12. Luminita Maria Gogan*, Alin Artene, Ioana Sarca, Anca Draghici, 2016, The Impact of Intellectual Capital on Organizational Performance , Procedia Social and Behavioral Sciences 221 ( 2016 ) $194-202$ 


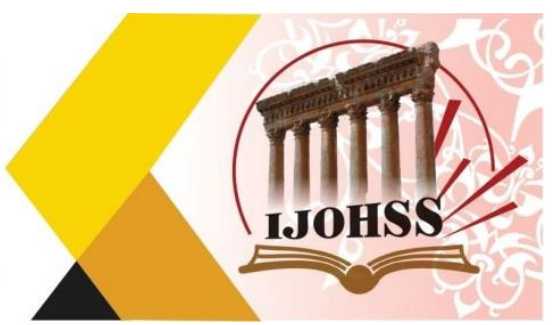

13. Alfranca, Ó., Diaz-Balteiro, L., \& Herruzo, A. C. (2009), "Technical innovation in Spain's wood-based industry: The role of environmental and quality strategies", Forest Policy and Economics, 11(3), 161-168.

14. Al-Jinini, D. K., Dahiyat, S. E., \& Bontis, N. (2019), "Intellectual capital, entrepreneurial orientation, and technical innovation in small and medium-sized enterprises", Knowledge and Process Management, 26(2), 69-85.

15. Ayoub, H. F., Abdallah, A. B., \& Suifan, T. S. (2017), "The effect of supply chain integration on technical innovation in Jordan", Benchmarking: An International Journal., Vol. 24 No. 3, pp. 594-616.

16. Carayannis, Elias G. \& Gonzalez, Edgar (2003), "Creativity and Innovation= Competitiveness? When, How, and Why", The International Handbook on Innovation, Larisa V. Shavinina (ed.), Part VIII, pp. 587-606.

17. Chen, J., Zhou, J., Xu, F., \& Yin, Y. (2013), "Technical and non-technical innovation models in China's SMEs: A case study", IEEE International Conference on Industrial Engineering and Engineering Management, pp. 1495-149).

18. Danish, R. Q. \& Holbrook, A. \& Latif, Y. \& Shaheen, U. (2016), "Impact of intellectual capital on organizational creativity through technical innovation in telecom sector sizes", Journal of Statistics, Vol. 23, No. 1, pp. 17-31.

19. Dengbo, Zhang \& Wulamu, Aziguli \& Lixin, Gao (2008), "Research of Methodology and Theory of Non-Technical Innovation", 4th International Conference on Wireless Communications, Networking and Mobile Computing, IEEE. 20. Fried, A., Gey, R., Pretorius, A., \& Günther, L. (2013), "Decoupling from standards-process management and technical innovation in software development organizations", International Journal of Innovation Management, 17(04), 1350012.

21. Garcia, R., \& Calantone, R. (2002), “A critical look at technological innovation typology and innovativeness terminology: a literature review", Journal of Product Innovation Management: An international publication of the product development \& management association, 19(2), 110-132.

22. Guohong, C., \& Ying, J. (2010), "Analysis of Technical Innovation Capability for Eight Economic Regions in China", 3rd International Conference on Information Management, Innovation Management and Industrial Engineering, IEEE, Vol. 4, pp. 56-59.

23. Hu, Jian Qiang \& Pan, Yue You \& Jiang, Liao(2013), "Technical innovation of rural tourism in zhejiang: a case study of Baisha village, Hangzhou city", Advanced Materials Research, Trans Tech Publications, Vol. 807, pp. 17211724 .

24. Kafetzopoulos, Dimitrios \& Psomas, Evangelos (2016), “Organisational learning, non-technical innovation and customer satisfaction of SMEs", International Journal of Innovation Management, Vol. 20, No. 03. 


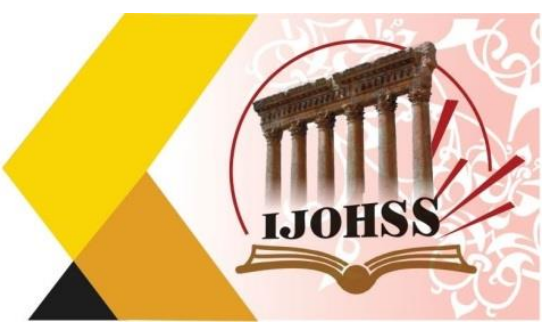

25. Koleva, K., \& Toteva-Lyutova, P. (2018), "Greenhouses automation as an illustration of interdisciplinarity in the creation of technical innovations", Procedia Manufacturing, 22, 923-930.

26. Ling, W. (2011), "New product development and technical innovation of China's trade", In MSIE, IEEE, pp. 1352-1355.

27. Lou, C. C., Lee, T. P., Gong, S. C., \& Lin, S. L. (2010), "Effects of technical innovation on market value of the US semiconductor industry", Technological forecasting and social change, 77(8), 1322-1338.

28. Madanmohan, T. R. (2005), "Incremental technical innovations and their determinants", International Journal of Innovation Management, 9(04), 481-510.

29. Palcic, Iztok \& Koren, Rolando \& Buchmeister, Borut (2015), "Technical innovation concepts in Slovenian manufacturing companies", Procedia Engineering, Vol. 100, pp. 141-149.

30. Rahmouni, M. (2011), "Déterminants du comportement d'innovation des entreprises en Tunisie", (Doctoral dissertation, Bordeaux 4).

31. Ramadan, B. M., Dahiyat, S. E., Bontis, N., \& Al-Dalahmeh, M. A. (2017), "Intellectual capital, knowledge management and social capital within the ICT sector in Jordan", Journal of Intellectual Capital, Vol. 18 No. 2, pp. 437-462.

32. SHI, Chun-sheng \& MENG, Da-peng. (2009), "Research on the Effects of Technical Innovation on Manufacturing Enterprise Competitiveness", International Conference on Management and Service Science, IEEE pp. 1-5.

33. Souitaris, Vangelis (2003), "Determinants of technological innovation: current research trends and future prospects", The international handbook on innovation, Vol. 7, No.07, pp. 513-528.

34. Teece, D. J. (2007), "Explicating dynamic capabilities: the nature and microfoundations of (sustainable) enterprise performance", Strategic management journal, 28(13), 1319-1350.

35. Wei, J. I. A., LIU, L. R., \& XIE, X. M. (2010). "Diffusion of technical innovation based on industry-university-institute cooperation in industrial clusters", The Journal of China Universities of Posts and Telecommunications, 17, 45-50. 